\title{
Biochar-templated surface precipitation and inner-sphere complexation effectively removes arsenic from acid mine drainage
}

\author{
Dongmei Wang ${ }^{1,2} \cdot$ Robert A. Root ${ }^{1} \cdot$ Jon Chorover ${ }^{1}$ \\ Received: 15 December 2020 / Accepted: 6 April 2021 / Published online: 18 April 2021 \\ (C) The Author(s) 2021
}

\begin{abstract}
Treatment of aqueous leachate from acid mine tailings with pristine biochar (BC) resulted in the removal of more than $90 \%$ of the dissolved arsenic with an attendant rapid and sustained $\mathrm{pH}$ buffering from 3 to 4 . Pine forest waste $\mathrm{BC}$ was transformed to a highly effective adsorbent for arsenic remediation of acid mine drainage (AMD) because the dissolved iron induced "activation" of BC through accumulation of highly reactive ferric hydroxide surface sites. Physicochemical properties of the BC surface, and molecular mechanisms of $\mathrm{Fe}, \mathrm{S}$, and As phase transfer, were investigated using a multi-method, micro-scale approach (SEM, XRD, FTIR, XANES, EXAFS, and STXM). Co-located carbon and iron analysis with STXM indicated preferential iron neoprecipitates at carboxylic BC surface sites. Iron and arsenic X-ray spectroscopy showed an initial precipitation of ferrihydrite on $\mathrm{BC}$, with concurrent adsorption/coprecipitation of arsenate. The molecular mechanism of arsenic removal involved bidentate, binuclear inner-sphere complexation of arsenate at the surfaces of pioneering ferric precipitates. Nucleation and crystal growth of ferrihydrite and goethite were observed after $1 \mathrm{~h}$ of reaction. The high sulfate activity in AMD promoted schwertmannite precipitation beginning at $6 \mathrm{~h}$ of reaction. At reaction times beyond $6 \mathrm{~h}$, goethite and schwertmannite accumulated at the expense of ferrihydrite. Results indicate that the highly functionalized surface of $\mathrm{BC}$ acts as a scaffolding for the precipitation and activation of positively charged ferric hydroxy(sulf)oxide surface sites from iron-rich AMD, which then complex oxyanion arsenate, effectively removing it from porewaters.
\end{abstract}

Keywords Biochar $\cdot$ Mine tailings $\cdot$ Arsenic sorption $\cdot$ Iron hydroxide activation · Acidic mine drainage

\section{Introduction}

Release of toxic metal(loid)s from mine tailings via acid mine drainage (AMD) occurs as a result of dissolution and colloidal dispersion, both of which pose significant risk to human health if introduced to neighboring ecosystems, groundwater,

Responsible Editor: Zhihong Xu

Jon Chorover

chorover@arizona.edu

Dongmei Wang

dongmeiwang@swjtu.edu.cn

Robert A. Root

rroot@arizona.edu

1 Department of Environmental Science, University of Arizona, 1177 E 4th St, Shantz 429, Tucson, AZ 85721, USA

2 Department of Environmental Engineering, Southwest Jiaotong University, Chengdu 610031, China or drinking water supplies. Among the toxic metal(loid)s, arsenic is of particular concern due to its acute toxicity to humans (ATSDR 2011). Arsenic contamination in mineralized regions, and concentrated in tailing dams by beneficiation activity, has resulted in the degradation of proximal surface water, groundwater, and soil, requiring extensive and expensive remedial action (Carlin et al. 2016). Containment is an effective management strategy at point sources of contamination, and successful efforts to amend mine tailings and AMD in-place to decrease risks of human health include excavation, capping, phytostabilization, and permeable reactive barriers (Hammond et al. 2018; Hu et al. 2019; Li et al. 2018; Mendez and Maier 2008; Valentin-Vargas et al. 2013). However, costs and unanticipated knock-on effects of remedial strategies compel further investigations into effective health risk mitigation (Hammond et al. 2020).

Due to its high specific surface area, micro-porosity, and benign character, biochar (BC) or black carbon has been promoted as a potential inexpensive sorbent for remediation of contaminated soil and waste streams (Ibrahim et al. 2016; Liu 
et al. 2019; Meng et al. 2018; Puga et al. 2016). Biochar is a sustainable product of pyrolyzed waste biomass, including agricultural and forestry residues (Artiola et al. 2012; Kelly et al. 2014; Liang et al. 2016). Wood biochar is dominated by highly aromatic structures with a relatively high specific surface area (between 350 and $400 \mathrm{~m}^{2} \mathrm{~g}^{-1}$ ) and variable pore volume. Pyrolysis induces dihydroxylation and dehydration reactions that confer alkalinity and precipitation of mineral solids from the biomass including quartz, calcite, and hydroxyapatite (Lehmann and Joseph 2009). Characteristics of the BC surface include reactive (including carboxylic and phenolic) organic functional groups, net negative surface charge, and high interfacial $\mathrm{pH}$, making it a high-affinity absorbent for cations (Beesley et al. 2010; Lehmann and Joseph 2009; Lu et al. 2016). Oxygen-containing BC functional groups can act as Lewis acids that accept electrons during complex formation, generating a $\mathrm{pH}$-dependent charge and even a redox active surface. The basal planes of graphitic micro sites have a high affinity for sorption of transition metal cations via pi-electron bonding (Brennan et al. 2001). The BC interface with aqueous solutions includes surface functional groups, surface radicals, and surface charge, all of which provide important reactive sites for surface complexation reactions (Xiao et al. 2018).

$\mathrm{BC}$ has been successfully deployed for the remediation of contaminated military ranges, agricultural soils, and industrial waste streams (Ahmad et al. 2016; Li et al. 2018; Uchimiya et al. 2012). Studies have indicated that transition metal cations (e.g., $\mathrm{Cu}^{2+}, \mathrm{Pb}^{2+}, \mathrm{Zn}^{2+}$ ) can be effectively immobilized by adsorption to BC (Beesley et al. 2010; Li et al. 2019). Far fewer studies have focused on the adsorption of metalloid oxyanions because BC exhibits net negative surface charge, and it has been shown to be a low-affinity sorbent for anionic contaminants (Amen et al. 2020). However, results are equivocal. For example, the use of BC as an amendment in an arsenic-contaminated soil-plant system showed diminished arsenic uptake to plants but increased mobilization into soil pore water (Beesley et al. 2013). This was likely due to BC acting as a source of phosphate, which competes with surface sites for arsenate sorption on soil, and preferential uptake of $\mathrm{PO}_{4}{ }^{3-}$ over $\mathrm{AsO}_{4}{ }^{3-}$ (Zhao et al. 2019b). Conversely, ternary complex formation, wherein $\mathrm{BC}$ serves as an adsorbent for cationic metals or nanoparticulate metal precipitates that could, in turn, present high-affinity complexation sites to adsorptive $\mathrm{AsO}_{4}{ }^{3-}$ species, could potentially transform the BC surface to an effective adsorbent for $\mathrm{AsO}_{4}{ }^{3-}$ (Yoon et al. 2017). For example, the use of engineered BC impregnated with magnetite has been shown to effectively remove aqueous arsenate (Zhang et al. 2013; Bakshi et al. 2018), where the mass ratio of $\mathrm{Fe}$ to $\mathrm{BC}$ ranged from $1: 1$ to $3: 1$. Wang et al. (2015) added hematite to $\mathrm{BC}$ at a mass fraction of $0.03 \mathrm{Fe}$ and used the composite media for arsenate removal. These techniques utilized the $\mathrm{BC}$ as a scaffolding to support added, active ferrous hydroxide particles and associated surface sites for arsenate removal.

In the presence of elevated dissolved ferric and ferrous iron, as occurs in AMD, the adsorption of $\mathrm{Fe}^{3+}$ at solid surfaces can initiate surface nucleation and crystal growth of ferric (hydr)oxides. Because iron (hydr)oxides and hydroxysulfates are among the most well-known and effective sorbents for immobilizing inorganic arsenic (Dixit and Hering 2003; Root et al. 2007; Wu et al. 2018), we postulated that biochar could be an effective remedial material for arsenic removal in Fe-bearing AMD waters. Specifically, we hypothesized that it would serve as a templating agent for surface nucleation of reactive ferric solids, and once activated by surface coating, $\mathrm{BC}$ would then promote surface complexation and removal of arsenic from the aqueous phase. If effective, such an approach, which would be leveraging the composition of the AMD waste stream itself to make BC a high-affinity adsorbent for arsenic, could be used at relatively low cost and with minimal complexity to remediate arsenic-bearing AMD.

The goal of this work was to evaluate the performance of unaltered BC on arsenic immobilization from AMD generated from metalliferous tailings derived from a sulfide ore deposit. The molecular mechanisms whereby arsenic may be immobilized from AMD waters using unamended BC have not been reported previously, but the presence of dissolved iron originating from mine waters that can subsequently react with $\mathrm{BC}$ provides an ideal opportunity to examine the nature and function of iron activation for arsenic removal that would also be applicable to other contaminated sites dominated by pyritic mineralogy.

\section{Materials and methods}

\section{Preparation and characterization of mine tailing water}

Mine tailings were collected from the top $0-30 \mathrm{~cm}$ at the Iron King Mine-Humboldt Smelter Site (IKMHSS) Superfund Site, located in central Arizona, USA. The tailings have been well-characterized and contain high levels of arsenic (3 g $\mathrm{kg}^{-1}$ ) and iron (120-150 $\mathrm{g} \mathrm{kg}^{-1}$ ) (Hayes et al. 2014; Root et al. 2015). The tailings were field screened to $2.5 \mathrm{~cm}$, homogenized, and further sieved to $2-\mathrm{mm}$ fines. The acid potential (AP) of the tailings was calculated from the mass of pyritic sulfur in the tailings, where total S was determined by total digestion and inductively coupled plasma mass spectrometry (ICP-MS) analysis, and the pyrite fraction determined by synchrotron X-ray absorption near edge structure (XANES) spectroscopy (Solis-Dominguez et al. 2012). Mine tailing pore water (MTW) was extracted by reacting tailing fines with 18.2 $\mathrm{M} \Omega \mathrm{m}^{-1}$ deionized water (Milli-Q, Barnstead) at $25^{\circ} \mathrm{C}$ for $24 \mathrm{~h}$ in a gentle end-over-end rotator $(7 \mathrm{rpm})$ at a solid to 
solution mass ratio of $100 \mathrm{~g} \mathrm{~kg}^{-1}$. After the reaction, the mixed solution was centrifuged at 28,000 relative centrifugal force (RCF) for $30 \mathrm{~min}$, pelletizing particles with Stokes' radii > $0.02 \mu \mathrm{m}$. The supernatant MTW solution was aspirated and used in subsequent experiments. Physiochemical parameters and soluble element concentrations were collected in the University of Arizona Laboratory for Emerging Contaminants (ALEC). Measurements of $\mathrm{pH}$ and EC were completed with daily-calibrated electrodes (Orion, epoxy semi-micro electrode). Metal(loid) concentrations were determined by ICP-MS (Perkin Elmer DRC-II) after microwaveassisted (Mars6, CEM) nitric acid digestion. Dissolved arsenic was previously determined to be arsenate $\left(\mathrm{As}^{5+}\right)$ by highpressure liquid chromatography (HPLC, Perkin Elmer Series 200, Hamilton PRX-P column) followed by ICP-MS detection. The dissolved $\mathrm{Fe}^{2+}$ was quantified using the ferrozine assay ( $1 \% \mathrm{w} / \mathrm{v}$ ferrozine in $50 \% \mathrm{w} / \mathrm{v}$ ammonium acetate) with UV detection (Stookey 1970). Analyses of TIC and TOC were by Shimadzu TOC-VCSH analyzer (Columbia, MD). Anion concentrations were measured by ion chromatography (Dionex DX-500, Sunnyvale, CA) with an AS-11 column and a $\mathrm{NaOH}$ mobile phase. Detailed properties of the MTW and mine tailings are given (Table S1).

\section{Preparation and characterization of BC}

Biochar was produced from pine forest wastes (including ponderosa pine wood chips, bark, small branches, and pine needles visible to the naked eye) using slow pyrolysis in batch mode with an interparticle temperature of 450 to $500{ }^{\circ} \mathrm{C}$ (Artiola et al. 2012). Pyrolyzed particulate samples were sieved to a 1-mm mesh and stored at room temperature. The $\mathrm{pH}$ and $\mathrm{EC}$ of the $\mathrm{BC}$ were measured following $24 \mathrm{~h}$ reaction in aqueous suspension $\left(100 \mathrm{~g} \mathrm{~kg}^{-1}\right)$ using $18.2 \mathrm{M} \Omega \mathrm{m}^{-1}$ deionized (Milli-Q, Barnstead) water. Samples were centrifuged and the aspirated supernatant solution was filtered using a $0.22-\mu \mathrm{m}$ GHP membrane prior to analysis by ICP-MS and IC as above. Detailed properties of the $\mathrm{BC}$ are given in the SI (Table S2). The dissolved organic carbon (DOC) generated by unreacted pine forest waste $\mathrm{BC}$ was extracted by separately reacting $1 \mathrm{~g}$ of BC sieved to $<250 \mu \mathrm{m}$ with $20 \mathrm{~g}$ of DI water $\left(18.2 \mathrm{M} \Omega \mathrm{m}^{-1}\right)$ in an end-over-end rotator $(7 \mathrm{rpm})$ for $24 \mathrm{~h}$. The suspension was passed through a $1.2-\mu \mathrm{m}$ glass fiber filter (GF/C, Whatman) and characterized by STXM and CNEXAFS (described in "Characterization of the solid phase").

\section{Batch kinetic experiments}

Kinetic adsorption experiments were performed in triplicate to assess arsenic removal by $\mathrm{BC}$ as a function of contact time by adding $0.1 \mathrm{~g}$ BC to $10 \mathrm{~g}$ of MTW in metal-free $50-\mathrm{mL}$ polypropylene vessels (VWR) at room temperature $\left(25 \pm 0.5^{\circ} \mathrm{C}\right)$ in an end-over-end rotator (7 rpm). Sacrificial batch reactors were sampled at pre-determined intervals $(0,15 \mathrm{~min}, 30 \mathrm{~min}$, $1 \mathrm{~h}, 2 \mathrm{~h}, 6 \mathrm{~h}, 12 \mathrm{~h}, 24 \mathrm{~h}$, and 48 h). Suspensions were analyzed for $\mathrm{pH}$ and then centrifuged at 28,000 RCF. The supernatant was aspirated and filtered through $0.22 \mu \mathrm{m}$ pore size GHP filters for arsenic and iron analyses. The solids were lyophilized at $-40{ }^{\circ} \mathrm{C}$ and 0.130 mbar for subsequent bulk and micro-focused analysis.

To evaluate the effect of $\mathrm{pH}$ on arsenic removal, MTW was adjusted to designated $\mathrm{pH}$ values between 1.5 and 8 with $0.1 \mathrm{M} \mathrm{NaOH}$ and $\mathrm{HCl}$ immediately prior to the addition of BC. After $24 \mathrm{~h}$ reaction, the suspensions were centrifuged and filtered through $0.22-\mu \mathrm{m}$ filters for arsenic analysis. The extended buffering capacity of BC was monitored with MTW + $\mathrm{BC}$ adjusted to $\mathrm{pH} 3$ with $\mathrm{HCl}$ at intervals of $0 \mathrm{~h}, 0.5 \mathrm{~h}, 4 \mathrm{~h}$, and $24 \mathrm{~h}$ and the serial $\mathrm{pH}$ response measured (Fig. S1). Controls with no $\mathrm{BC}$ were examined to evaluate the isolated effect of $\mathrm{pH}$ on arsenic solubility and complexation in the absence of BC (Fig. S2).

Geochemical modeling was used to calculate aqueous phase iron speciation under the kinetic batch experimental conditions, and to investigate the relation between the observed and thermodynamically predicted mineral phases using Geochemist's Workbench (GWB) package v 9 with the Lawrence Livermore National Laboratory (LLNL) thermodynamic database thermo.com.v8.r6+ (Bethke 2008; Delany and Lundeen 1990), modified with solubility data for schwertmannite and plumbojarosite (Forray et al. 2014; Majzlan et al. 2006) (Table S3). Activity-activity phase relationship diagrams were calculated using the ACT2 program with activity coefficients calculated with the extended DebyeHuckle B-dot method (Helgeson et al. 1981).

\section{Characterization of the solid phase}

X-ray diffraction Control BC (DI reacted only); MTW-BC at 12,24 , and $48 \mathrm{~h}$; and MTW-BC reacted for $24 \mathrm{~h}$ with the $\mathrm{pH}$ adjusted from 1.5 to 8 were prepared for powder X-ray diffraction by placing about $50 \mathrm{mg}$ of lyophilized and ground $\mathrm{BC}$ between two layers of clear cellulose tape (Scotch Magic ${ }^{\mathrm{TM}}$ ). Laue patterns were collected on a large array CCD (MAR3450) detector at the Stanford Synchrotron Radiation Lightsource (SSRL) at beam line 11-3 operating at $500 \mathrm{~mA}$ and $12735 \mathrm{eV}(\lambda=0.976 \AA)$. Three exposures of $60 \mathrm{~s}$ were collected while the sample was rastered $2 \mathrm{~mm}$ in $x$ and $y$, normal to the incident beam and averaged. Calibration, geometric corrections, and conversion of the 2-D images to 1-D 2theta diffractograms were performed with Igor Pro v 8.02 (WaveMetrics, Inc.) using the Nika v1.81 add-on (Ilavsky 2012). The energy was converted to $\mathrm{Cu}-\mathrm{K} \alpha$ radiation for comparison with conventional mineral standards using X-Pert HighScore Plus software (PANalytical). Diffractograms were normalized to the maximum broad carbon (002) peak at $3.4 \AA$. Inorganic crystalline phases were identified with reference 
minerals from the International Centre for Diffraction Data Powder Diffraction File (ICDD PDF-2) database (ICDD 2005).

STXM and C NEXAFS Scanning transmission X-ray microscopic (STXM) analysis of the lyophilized MTW reacted BC solids was performed at the SM beamline (10ID-1) at the CLS, as above for the DOC. Briefly, about $1 \mu \mathrm{L}$ of the MTW-BC solids in suspension was deposited onto a 100$\mathrm{nm}$-thick silicon nitride window $(1 \times 1 \mathrm{~mm})$ and allowed to air-dry. Stacked maps were collected with a $100-$ to $150-\mathrm{nm}^{2}$ pixel size at incremental energies across the $\mathrm{C} \mathrm{K}$-edge, and difference maps were collected above and below (presenceabsence) the $\mathrm{Fe}$ and As L-edges, although As was not detected. Collected images were converted to optical density by normalization to an absorbance-free $\left(\mathrm{I}_{0}\right)$ region, and NEXAFS spectra were extracted at each pixel from stacked maps collected across the C K-edge and Fe Ledge and analyzed using principal component and cluster analysis in the MANTiS software package (Lerotic et al. 2014). Incident energy was calibrated with $\mathrm{CO}_{2}$ at 290.74 $\mathrm{eV}$. Pseudo-Voigt profile curve-fitting was used to assign peak position $( \pm 0.3 \mathrm{eV})$ and FWHM using the software package Athena (Ravel and Newville 2005). Peak positions were assigned by comparison with literaturereported values (Lehmann et al. 2005).

X-ray absorption spectroscopy (XAS) Iron and arsenic K-edge XAS were collected with a 100 -element Ge array detector, a Si (220) phi $=90$ double-crystal monochromator, and 2-mm vertical beam slits at Stanford Synchrotron Radiation Lightsource (SSRL) beam line 11-2. Energy was calibrated for iron and arsenic with the first inflection of the white line absorbance of an iron foil defined as $7112 \mathrm{eV}$, and the first inflection of the absorbance of a gold foil defined as 11,919 $\mathrm{eV}$, respectively. Lyophilized, unreacted $\mathrm{BC}$ and MTW-BC were ground, loaded into aluminum sample holders, sealed with Kapton tape, and placed in an $\mathrm{LN}_{2}$ cryostat, with spectra acquired to $k=13.5$ using $0.35 \mathrm{eV}$ energy steps in the XANES region. All scans $(n \geq 4)$ were averaged using the SIXPACK software package (Webb 2006). Spectra were background subtracted, normalized, and quantitatively analyzed by linear combinations fitting (LCF) using reference minerals collected under similar conditions using the Athena software package (Ravel and Newville 2005). The first derivatives of normalized Fe XANES spectra were fit with a range of 7100-7150 $\mathrm{eV}$. After visual inspection and comparisons of different combinations of reference spectra, the final reference spectra included ferrihydrite, goethite, schwertmannite, and unreacted BC. Arsenic XAS were fit by LCF to reference arsenate sorbed ferric mineral specimens. To further examine the local bonding environment of arsenic at the $\mathrm{BC}$ surface, shell-byshell fits of the $k^{3}$ extended X-ray absorption fine structure
(EXAFS) by non-linear least squares methods in $k$-space (3$12.5 \AA^{-1}$ ) were performed with the Artemis software package (Ravel and Newville 2005). Phase-shift and amplitude functions were calculated with the program FEFF8 with selfconsistent calculations (Rehr 1993) using atomic clusters taken from the crystal structures of angelellite $\left[\mathrm{Fe}^{\mathrm{III}}{ }_{4}\left(\mathrm{As}^{\mathrm{V}} \mathrm{O}_{4}\right)_{2} \mathrm{O}_{3}\right]$. Multiple scattering paths from arsenate tetrahedra $\left(\mathrm{As}^{\mathrm{V}} \mathrm{O}_{4}\right)$, which have been shown to improve the As EXAFS fits, were included (Beaulieu and Savage 2005; Ona-Nguema et al. 2005). The unreacted BC had insufficient arsenic to obtain EXAFS spectra, but quality As XANES data were collected. The shell-by-shell fits were evaluated against the reduced chi and $R$-factor evaluation parameters, where minimization of the fitting parameters indicated a better correlation between the data and the adjusted variables, normalized by the degrees of freedom in the fit.

Fourier transform infrared (FTIR) spectroscopy Lyophilized samples were mixed with $\mathrm{KBr}$ at a 1:50 mass ratio, ground by mortar and pestle to homogenize, and pressed into 13-mmdiameter pellets (Spex SamplePrep) for mid-range FTIR spectroscopy (Nicolet 6700 spectrometer, Thermo). Transmission FTIR spectra were collected over the region of 400-4000 $\mathrm{cm}^{-1}$ using a $\mathrm{CO}_{2}$-free purge gas generator and a deuterated triglycine sulfate (DTGS) detector with 32 interferograms averaged for each spectrum. Data collection and spectral processing, including background subtraction and baseline correction, were performed using the OMNIC program (Thermo Nicolet, Co.).

Scanning electron microscopy with energy-dispersive spectroscopy (SEM-EDS) High-resolution micrographs were collected by field emission scanning electron microscope (FESEM, Hitachi S-4800 Type II) operated at $20 \mathrm{kV}$ with energy-dispersive $\mathrm{X}$-ray spectroscopy (EDS, Oxford) analysis collected at $10 \mathrm{kV}$. Samples of unreacted BC and MTW-BC (at $48 \mathrm{~h}$ ) were prepared on carbon tape and imaged under various magnifications at $7.5 \mathrm{~mm}$ working distance.

\section{Results}

\section{Mine tailing water}

Mine tailings from the IKMHSS Superfund site have an acidgenerating potential (AP) of $1.6 \mathrm{~kg} \mathrm{H}_{2} \mathrm{SO}_{4} \mathrm{Mg}^{-1}$ (SolisDominguez et al. 2012), and produce AMD from the oxidization of sulfides and hydrolysis of $\mathrm{Fe}^{3+}{ }_{(a q)}$. Water extracted from mine tailings was acidic and had elevated conductivity $\left(\mathrm{pH}=3.2( \pm 0.1), \mathrm{EC}=7.22( \pm 0.01) \mathrm{mS} \mathrm{cm}{ }^{-1}\right)$ (Table S1). The water-soluble inorganic and organic carbon values were $\left(48.7( \pm 1.1) \mathrm{mg} \mathrm{kg}^{-1}\right.$ and $59.9( \pm 1.4) \mathrm{mg} \mathrm{kg}^{-1}$, respectively). Dissolved arsenic in MTW was $7.7 \mu \mathrm{mol} \mathrm{kg}$ 
and dissolved iron was $24 \mathrm{mmol} \mathrm{kg}$. The oxidation state of arsenic in solution was $\mathrm{As}^{\mathrm{V}}$, which, at $\mathrm{pH} 3.2$, would be dominated by the oxyanion $\mathrm{H}_{2} \mathrm{AsO}_{4}{ }^{-}(\mathrm{pKa}=2.19)$. Dissolved iron was dominantly ferric $\left(\mathrm{Fe}^{3+}=\Sigma\left(\mathrm{FeOH}^{2+}, \mathrm{Fe}(\mathrm{OH})^{2+}, \mathrm{Fe}^{3+}\right)\right.$ with a small fraction of ferrous $(6.4 \%$ of total $\mathrm{Fe})$ (Table S1). Dissolved sulfur was dominantly sulfate, with total S concentration $=226 \mathrm{mmol} \mathrm{kg}^{-1}$.

\section{Arsenic adsorption kinetics}

The arsenic removal rate was analyzed by monitoring the solution chemistry of the MTW-BC reaction from $15 \mathrm{~min}$ to $48 \mathrm{~h}$ (Fig. 1). As the reaction progressed, $\mathrm{pH}$ rapidly increased from 3.2 to 4.0 and reached an apparent equilibrium within 2 h. Dissolved arsenic $\left([\mathrm{As}]_{0}=580 \mu \mathrm{g} \mathrm{kg}^{-1}\right)$ was removed from solution at each time step to the end of the experiment. At 48 $\mathrm{h}$, the concentration of arsenic in solution approached the limit of detection (Fig. 1). The adsorbate concentration $\left(Q, \mathrm{mg} \mathrm{g}^{-1}\right)$ as a function of time $(t)(\mathrm{min})$ was well described by a pseudosecond-order model $\left(R^{2}=0.985\right)$ (Fig. 1), and less well described by either a first-order expression $\left(R^{2}=0.833\right)$ or Elovich equation $\left(R^{2}=0.826\right)$ (Fig. S3), consistent with arsenic removal to a reactant that is not present in excess.

\section{Characterization of the reacted biochar}

Functional groups and treatment effects were identified for the unreacted BC and MTW-reacted BC for $1 \mathrm{~h}$ and at $48 \mathrm{~h}$ by FTIR spectroscopy (Fig. 2). FTIR spectra evolved with reaction time. A broad band centered at $c a .3400 \mathrm{~cm}^{-1}$, representing $\mathrm{O}-\mathrm{H}$ stretching, indicated abundant oxygencontaining functional groups in the $\mathrm{BC}$ (Yuan et al. 2011). After reaction with MTW, the intensity of the broad 3300$2500 \mathrm{~cm}^{-1}$ hydroxyl stretching band was reduced, and an increase centered at $3500 \mathrm{~cm}^{-1}$ was noted. The small feature at $1690 \mathrm{~cm}^{-1}$ increased with the MTW reaction time, attributed to $\mathrm{C}=\mathrm{O}$ stretching. The $\mathrm{C}=\mathrm{C}$ stretch from poly- aromatics at $1576 \mathrm{~cm}^{-1}$ was generally unchanged pre- and post-MTW reaction, indicating a stable aromatic biochar backbone structure. However, the band centered at 1437 to $1414 \mathrm{~cm}^{-1}$, assigned to $\mathrm{C}-\mathrm{O}$ stretching, shifts to higher frequency with reaction time in MTW, an observation that can be attributed to increased H-bonding in the acidic environment. The peaks at 1432,874 , and $748 \mathrm{~cm}^{-1}$, from the asymmetric $\mathrm{CO}_{3}$ stretch for calcite, were diminished in the MTW-BC, as expected by calcite dissolution induced by the acidic $\mathrm{pH}$ of the MTW. A small peak in the fingerprint region at $1050 \mathrm{~cm}^{-1}$, attributed to $\mathrm{C}-\mathrm{O}$ stretching, is removed after reaction with MTW, and a small, broad peak emerged upon MTW reaction at $605 \mathrm{~cm}^{-1}$, which could be attributed to $\mathrm{Fe}-\mathrm{O}$ stretching. Along with the diminished calcite peaks, the largest difference between the $\mathrm{BC}$ control and MTW-BC was the wide feature from approximately at $1100-1200 \mathrm{~cm}^{-1}$, a region generally assigned to sulfate, which was strengthened with increasing MTW-BC reaction time. The difference between the unreacted BC and MTW$\mathrm{BC}$ in this region was consistent with sorbed $\mathrm{SO}_{4}{ }^{2-}$ or precipitation of gypsum and/or schwertmannite (Fig. S4).

The X-ray diffractograms of the BC and MTW-BC (48 h) indicate the presence of inorganic quartz at 3.34 and $4.26 \AA$ $(011,100)$ in all BC samples (Fig. 3). Calcite was confirmed for reactions carried out at $\mathrm{pH}>3.5$ by Bragg reflections at $d$ spacings of 3.86, 3.03, 2.50, 2.28, 2.09, 1.91, and $1.87 \AA$ (Fig. S5, Table 1). The intense sharp peak at $3.03 \AA$ indicated that calcite was well crystallized. All biochar samples had broad features centered at $3.4 \AA$ (graphite [002]) and $2.0 \AA$ (graphite [001]), characteristic of turbostratic crystalline carbon. Identified solids in the unreacted $\mathrm{BC}$ were quartz $\left(\mathrm{SiO}_{2}\right)$, calcite $\left(\mathrm{CaCO}_{3}\right)$, graphite $(\mathrm{C})$, albite $\left(\mathrm{NaAlSi}_{3} \mathrm{O}_{8}\right)$, whewellite $\left(\mathrm{CaC}_{2} \mathrm{O}_{4} \cdot \mathrm{H}_{2} \mathrm{O}\right)$, and a peak associated with aromatic rings at $10 \AA$ (Table 1).

However, the mineral assemblage in $\mathrm{BC}$ was significantly altered following reaction with MTW. Peaks from calcite weakened or disappeared, due to the instability of carbonates
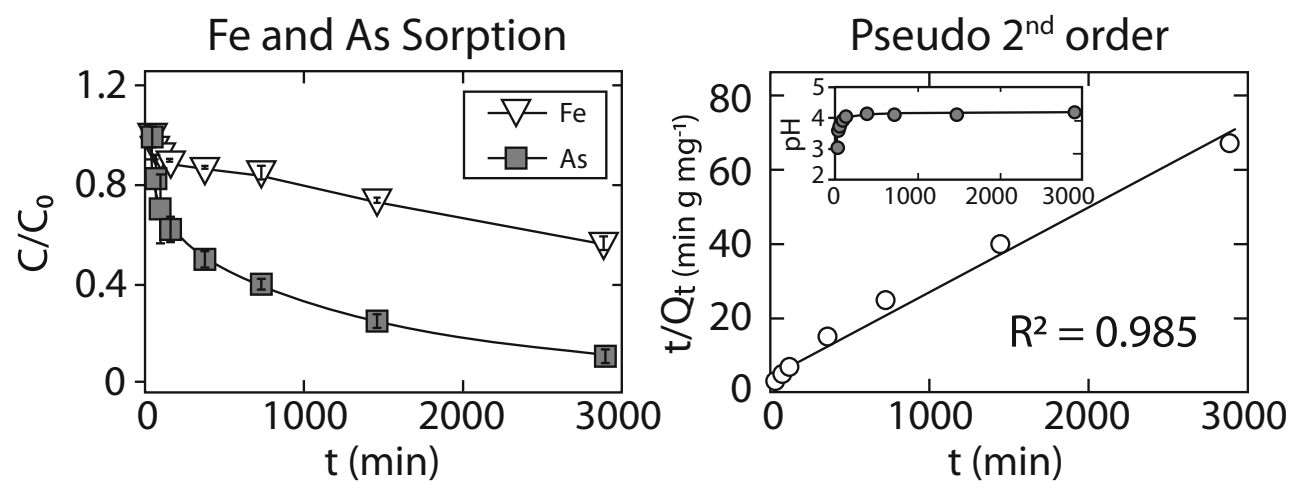

Fig. 1 Iron (open triangles) and arsenic (filled squares) removal from solution (left panel), with arsenic loss fit to pseudo-second-order rate expression (right panel), and reaction $\mathrm{pH}$ shown in inset. Error bars, generally smaller than the symbols, represent the standard deviation of

triplicate samples. $C / C_{0}$ is the fraction of $\mathrm{Fe}$ or As in solution, $t / Q_{t}$ (min $\mathrm{mg} \mathrm{g}^{-1}$ ) is the quotient of reaction time $t(\mathrm{~min})$ and adsorbate (As) concentration at time $t$ (Jin et al. 2020) 
Fig. 2 FTIR spectra of pine forest waste biochar before (black) and after reaction with MTW at $1 \mathrm{~h}$ (green) and $48 \mathrm{~h}$ (brown). Spectra are dominated by organic aromatic and aliphatic vibrations. Noteworthy changes include reduced $\mathrm{CO}_{3}$ vibrational bands, increased broad $\mathrm{SO}_{4}$ absorbance $\left(1100-1200 \mathrm{~cm}^{-1}\right)$, and increased free hydroxyl groups $(3550-3600$ $\mathrm{cm}^{-1}$ )

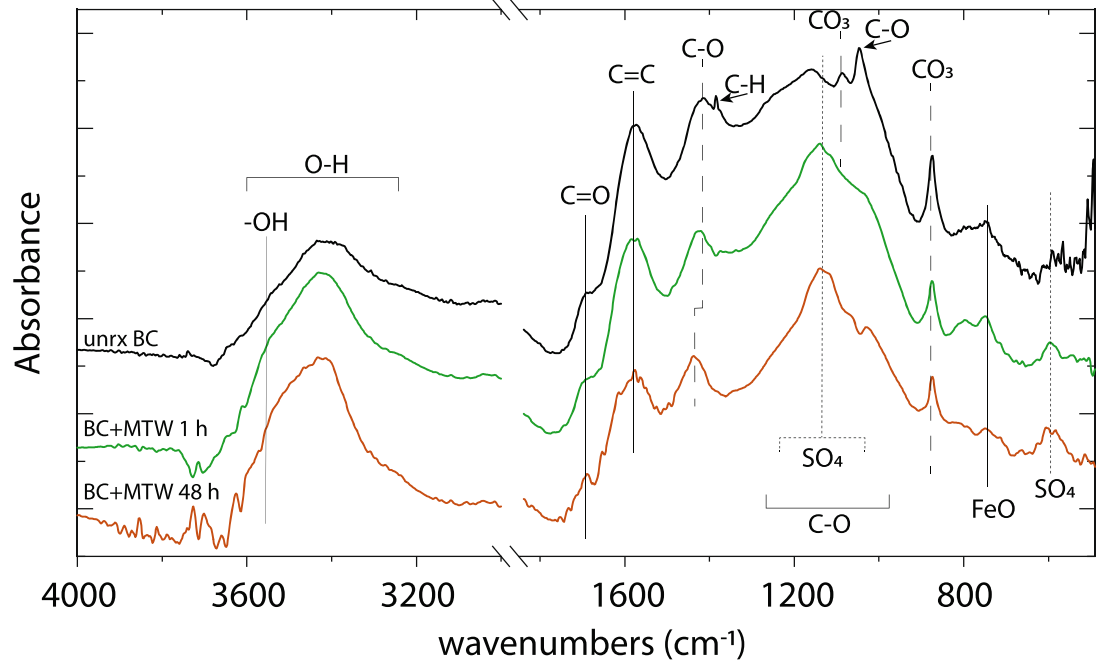

in the low-pH MTW. Similarly, calcium oxalate (whewellite) peaks diminished or disappeared in the acid MTW, indicating dissolution of these solids. Additionally, new peaks (4.27 $\AA$, $3.67 \AA, 3.53 \AA, 3.24 \AA, 2.69 \AA$ ) were observed in MTW-BC indicating precipitation of gypsum $\left(\mathrm{CaSO}_{4} \cdot 2 \mathrm{H}_{2} \mathrm{O}\right)$. Interestingly, no ferric solids were observed in the XRD patterns for MTW-BC. Since other data sources (discussed below) indicate ferric solid precipitation, this XRD result is

Table 1 Inorganic solids in biochar before and after reaction with mine tailing water (MTW)

\begin{tabular}{ll}
\hline Sample & Inorganic solids \\
\hline $\mathrm{BC}_{\mathrm{t} 0}$ (unrx) & Qz, Cal, Gr, Wh, Al \\
MTW-BC (h) & \\
12 & Qz, Gr, Gp, Cal, 10 \\
24 & Qz, Gr, Gp, Cal, 10 \\
48 & Qz, Gr, Gp, Cal, Al, 10 \\
pH & \\
1.5 & Qz, Gr, Gp, Al \\
2 & Qz, Gr, Gp, Al \\
2.5 & Qz, Gr, Gp, Al \\
3 & Qz, Gr, Gp, Cal, Al \\
3.5 & Qz, Gr, Gp, Cal, Al, 10 \\
4 & Qz, Gr, Gp, Cal, Al, 10 \\
5 & Qz, Gr, Gp, Cal, 10 \\
6 & Qz, Gr, Gp, Cal, 10 \\
7 & Qz, Gr, Gp. Cal \\
8 & Qz, Gr, Gp, Cal, Al \\
\hline
\end{tabular}

Solid phases determined by synchrotron transmission X-ray diffraction. $\mathrm{BC}_{\mathrm{t} 0}$ (unrx) is unreacted pine waste biochar. Kinetic series and $\mathrm{pH}$ series samples were reacted with mine tailing water (MTW). Unreacted and time series XRD shown in Fig. 3, pH series XRD in Fig. S5; $10 \AA$ aromatic is an undifferentiated peak characteristic of aromatic carbon rings. $Q z$ quartz, $C a l$ calcite, $G r$ graphite, $G p$ gypsum, $A l$ albite, $W h$ whewellite suggestive of low crystallinity or concentrations below detection of the neo-formed precipitates.

\section{Molecular speciation of carbon, iron, and arsenic}

The carbon character of MTW-BC (48 h) particles was analyzed by scanning transmission x-ray microscopy (STXM) and carbon $1 \mathrm{~s}$ near-edge $\mathrm{X}$-ray absorption fine structure $(\mathrm{C}$ NEXAFS) spectroscopy. Principal component analysis (PCA) from the stacked maps collected across the $\mathrm{C}$ 1s edge identified seven components, inclusive of the $\mathrm{I}_{0}$ carbon-free regions (Fig. 4). Normalized NEXAFS spectra were extracted for each PCA determined region (Fig. 4a), and per pixel analysis of the PCA regions indicated $31.4 \%$ of the image corresponded to the $\mathrm{I}_{0}$ background, and components $1-6$ accounted for 13.2, $10.8,13.2,10.8,14.0$, and $6.6 \%$ of the pixels in the map, respectively (Fig. 4b). Select C 1 s peak features are indicated with dashed vertical lines and labeled with roman numerals (Fig. 4a). The small peak at (I) $284 \mathrm{eV}$ is attributed to a quinone-C surface group $1 \mathrm{~s}-\pi^{*}(\mathrm{C}=\mathrm{O})$; (II) the large peak at $285.6 \mathrm{eV}$ is from aromatic- $\mathrm{C}$ ring $1 \mathrm{~s}-\pi^{*}(\mathrm{C}=\mathrm{C})$; (III) 287.4 is aliphatic-C $1 \mathrm{~s}-\sigma^{*}\left(3 \mathrm{p}_{\mathrm{C}-\mathrm{H}}\right)$; and (IV) $288.5 \mathrm{eV}$ assigned to carboxylic-C $1 \mathrm{~s}-\pi^{*}(\mathrm{C}=\mathrm{O})$ (Solomon et al. 2012). Maps in Fig. $4 \mathrm{~b}-\mathrm{d}$ are $10 \mu \mathrm{m}$ square with a $100-\mathrm{nm}^{2}$ pixel size; the iron map inset was $75 \mu^{2}$ with a $150-\mathrm{nm}^{2}$ pixel size. The regions with high iron correspond to PCA regions 2 and 3, which have $\mathrm{C}$ spectra that show strong carboxylic character (288.5 eV). The PCA regions 4, 5, and 6 are not correlated with iron and have $\mathrm{C}$ character similar to unreacted BC DOM (Fig. S6).

The solid-phase iron species were investigated by $\mathrm{Fe} \mathrm{K} \alpha$ XANES in the unreacted BC and in the MTW-BC samples collected at $15 \mathrm{~min}, 1 \mathrm{~h}, 6 \mathrm{~h}$, and $48 \mathrm{~h}$ (Fig. 5), with fractional components determined by linear combination fitting to the first derivative of XANES spectra (Table 1). The unreacted $\mathrm{BC}\left([\mathrm{Fe}]_{0}=821 \mathrm{mg} \mathrm{kg}^{-1}\right)$ XANES spectrum was used as the 


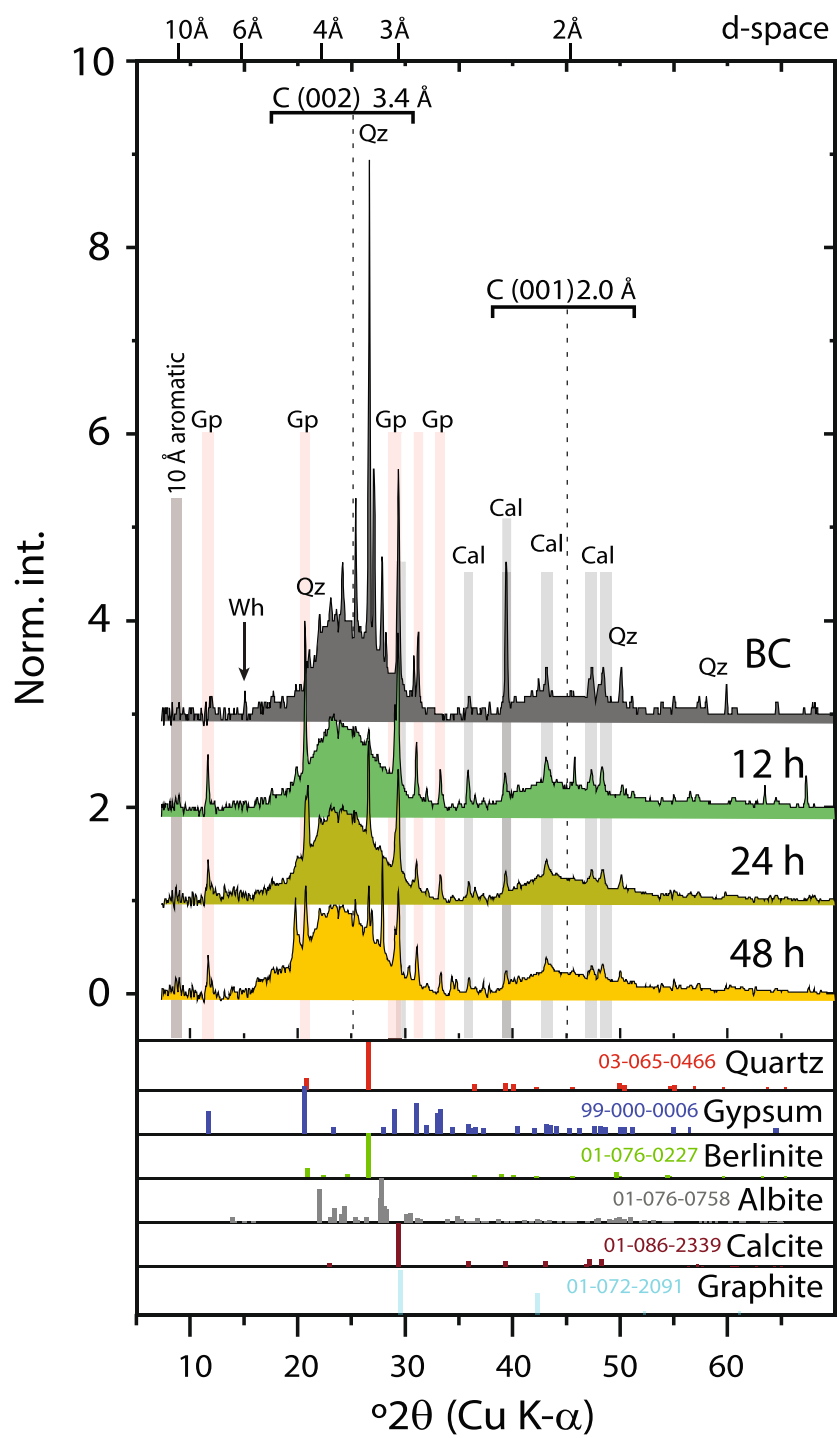

Fig. 3 X-ray diffraction patterns for the unreacted and MTW-reacted biochar. Diffractograms of unreacted BC and MTW-BC for 12, 24, and $48 \mathrm{~h}$, normalized to the maximum carbon (002) $3.4 \AA$ feature. The $x$-axis shows ${ }^{\circ} 2 \theta(\lambda=\mathrm{Cu})$; the top $x$-axis shows d-spacing $(\AA)$. Broad features indicative of turbostratic carbon are noted at 3.4 and 2.0 $\AA$. Cal = calcite, $\mathrm{Qz}=$ quartz, $\mathrm{Gp}=$ gypsum, and $\mathrm{Wh}=$ whewellite. The $10 \AA$ aromatic, an undifferentiated peak characteristic of aromatic carbon rings, increases relatively with reaction time. Standard minerals and the ICCD PDF codes are shown for reference

endmember component for fitting the reacted BC. Iron in MTW-BC reacted for 15 min was mostly that in unreacted $\mathrm{BC}(70 \%)$, but even at this first time point, ferrihydrite $\left[\mathrm{FeOOH}-\mathrm{Fe}_{10} \mathrm{O}_{14}(\mathrm{OH})_{2}\right]$ accounted for almost a third of the total iron $(30 \%)$. As the reaction progressed, the relative fraction of iron from unreacted $\mathrm{BC}$ decreased while the secondary iron (hydr)oxide component increased in prevalence with a concurrent change in speciation. Whereas ferrihydrite was identified at each time step ( $15 \mathrm{~min}$ to $48 \mathrm{~h}$ ), schwertmannite $\left(\mathrm{Fe}_{8} \mathrm{O}_{8}(\mathrm{OH})_{6} \mathrm{SO}_{4}\right)$ was identified when the reaction time reached $6 \mathrm{~h}$ and it remained at $48 \mathrm{~h}$. Goethite $(\alpha-\mathrm{FeOOH})$
Table 2 Iron speciation of $\mathrm{BC}$ for $0-48 \mathrm{~h}$ from XANES linear combination fitting

\begin{tabular}{llllll}
\hline $\begin{array}{l}\text { BC } \\
\text { sample }(h)\end{array}$ & \multicolumn{3}{l}{ Fit component $(\%)$} & $\begin{array}{l}R- \\
\text { factor }\end{array}$ \\
\cline { 2 - 5 } & BC & Fh & Sch & Goe & \\
\hline 0 & 100 & - & - & - & NA \\
0.25 & 70 & 30 & - & - & 0.0348 \\
1 & 60 & 24 & - & 16 & 0.0095 \\
6 & 40 & 16 & 13 & 30 & 0.0119 \\
48 & 30 & 23 & 15 & 32 & 0.0129 \\
\hline
\end{tabular}

Sample 0 , the unreacted biochar (BC at $t=0 \mathrm{~min}$ ), was used as a fit component in reacted $\mathrm{BC}$ samples; the iron mineral fit components $\mathrm{Fh}$ $=$ ferrihydrite, $\mathrm{Sch}=$ schwertmannite, and Goe $=$ goethite were from Hayes et al. (2014). The $R$-factor represents the mean square misfit between the data and the fit. Component fits were normalized to unity

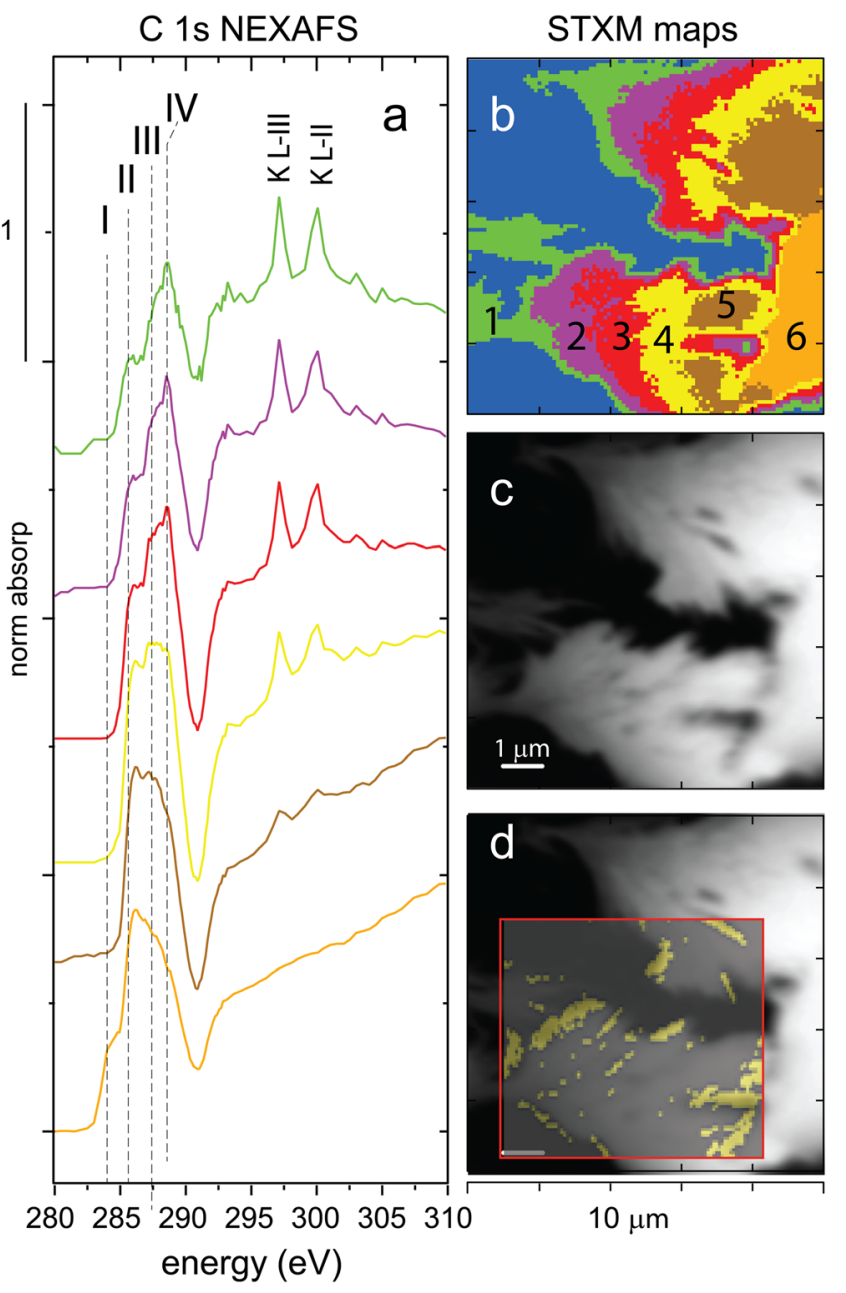

Fig. 4 Mine tailing water reacted biochar (MTW-BC) carbon 1s NEXAFS and STXM stacked maps. a C-NEXAFS spectra of PCAdetermined components; $\mathbf{b}$ spatial distribution of components in $\mathbf{a} ; \mathbf{c}$ STXM submicron resolution optical density image; d Fe-rich regions overlaying the C map. NEXAFS features I-IV highlight specific carbon components (Lehmann et al. 2005). The peaks at 297.4 and 299.7 are the L-III and L-II peaks of potassium. Please refer to the electronic version for color 
Fig. 5 Normalized first derivative iron K- $\alpha$ XANES. a Reference spectra. b MTW-BC reacted sample spectra. Data shown with black lines, linear combination fits (LCF) to reference spectra shown in dashed red lines, LCF fits given in Table 2

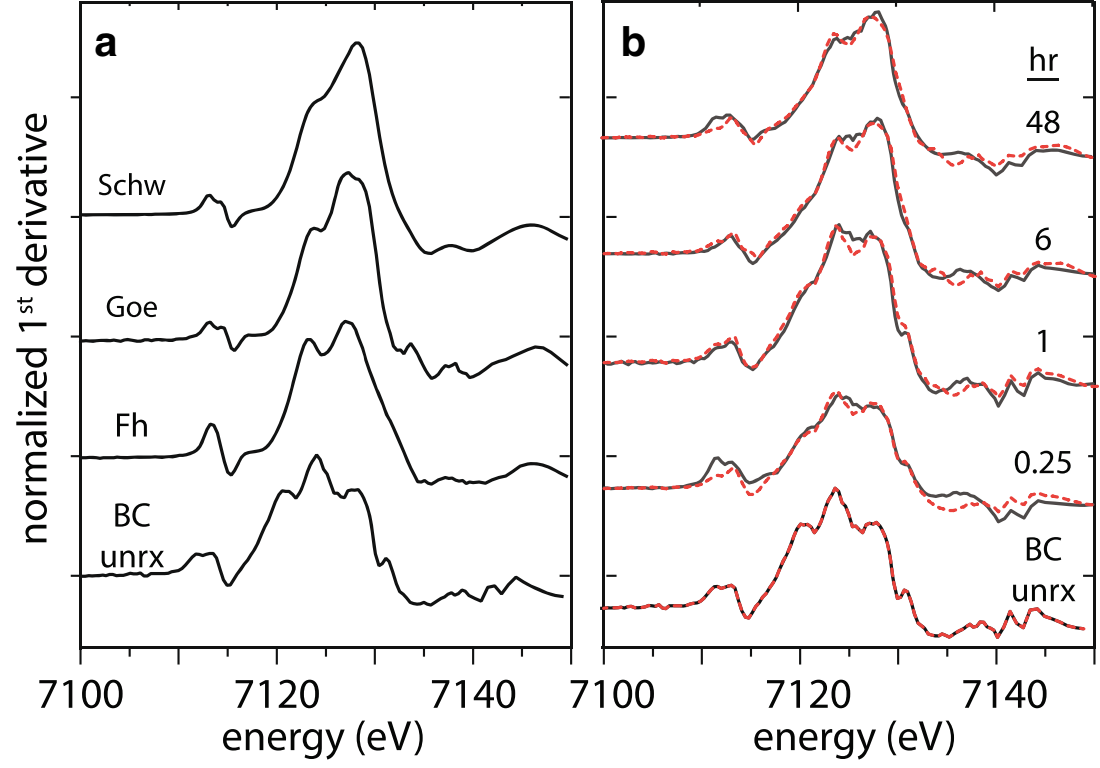

was fit to the spectra when the reaction time reached $1 \mathrm{~h}$, and the goethite fractional contribution to the Fe XANES increased from 1 to $6 \mathrm{~h}$ and remained about one third of the iron signal from 6 to $48 \mathrm{~h}$.

The oxidation state and speciation of arsenic in $\mathrm{BC}$ and MTW-BC were measured with X-ray absorption spectroscopy (XAS). XANES indicated the oxidation state was all pentavalent $\left(\mathrm{As}^{\mathrm{V}}\right.$, i.e., arsenate), with an absence of either arsenite, arsenic sulfide, or thiol complexes (Fig. 6). The initial BC had trace arsenic content $\left(0.60 \pm 0.10 \mathrm{mg} \mathrm{kg}^{-1}\right)$, which was also determined by XANES to be arsenate. Arsenic EXAFS of MTW-BC were examined by LCF and showed good correlation ( $R$-factor 0.0999$)$ with a combination of $\mathrm{As}{ }^{\mathrm{V}}$ sorbed goethite, ferrihydrite, and schwertmannite (Fig. S7). However, the coordination of arsenate tetrahedra at ferric hydroxide octahedra surface sites are very similar across these three ferric solids, and hence, the EXAFS are very similar as well. Therefore, while we can conclude that arsenate is adsorbed at $\mathrm{Fe}^{\mathrm{III}}$ octahedral sites of mineral plaques formed on the $\mathrm{BC}$ surface, LCF has limited applicability for quantitatively deconvolving the relative contribution of these three ferric solids to that arsenate adsorption. The BC, with low arsenic, was sufficient for arsenate speciation by XANES, but the EXAFS signal to noise was too poor for shell-by-shell fitting. Conversely, the MTW-BC produced As K $\alpha$ EXAFS that were fit with a first coordination shell of 4.0 oxygen atoms at a distance of $1.69 \AA$, characteristic of the $\mathrm{As}^{\mathrm{V}}-\mathrm{O}_{4}$ tetrahedra and in agreement with the assignment of arsenate by XANES.

As EXAFS fit details are provided in Table S4. The arsenic second shell was best fit with 1.2 Fe backscatters
Fig. 6 Arsenic K-edge XAS of $\mathrm{BC}$ and MTW-BC (48 h) and reference compounds: XANES (left), $k^{3}$-weighted EXAFS (center), and Fourier transformed radial distribution function (right). Data shown with black lines, fits to data shown in dashed red lines. Model compounds include scorodite, $\mathrm{As}^{\mathrm{v}}$ on goethite, $\mathrm{As}^{\mathrm{v}}$ on ferrihydrite, $\mathrm{As}^{\mathrm{v}}$ coprecipitated with schwertmannite, and As ${ }^{\mathrm{III}}$ on ferrihydrite. Arsenic speciation is indicated in the XANES panel with vertical lines corresponding to the reference minerals: arsenite as $\mathrm{As}{ }^{(\mathrm{III})}$-Fh is the blue dashed line, and arsenate as $\mathrm{As}^{(\mathrm{V})}-\mathrm{Fh}$ is the red dashed line. EXAFS fit details in Table S4. See electronic version for color
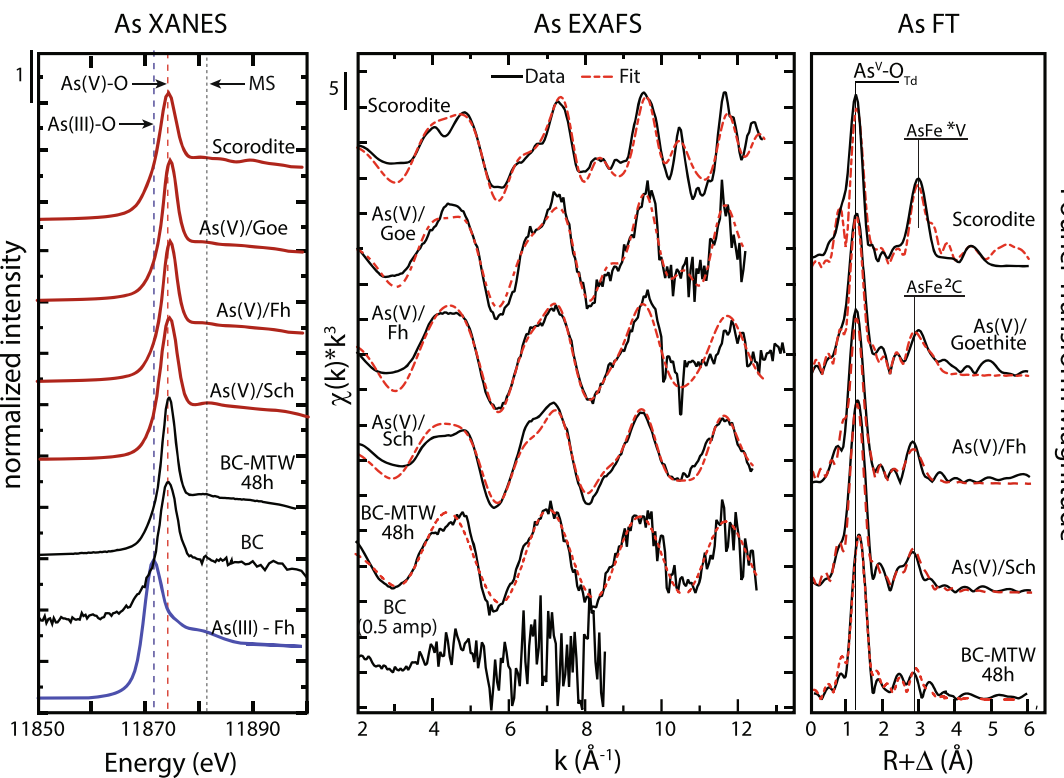
at $3.37 \AA$, a distance longer than model studies with $A s^{\mathrm{V}}$ coprecipitated with ferrihydrite (Gao et al. 2013), but consistent with bidentate-binuclear corner linkage $\left({ }^{2} \mathrm{C}\right)$ of $\mathrm{As}^{\mathrm{V}}-\mathrm{Fe} \mathrm{III}^{\mathrm{II}}$ at a distance of $\sim 3.3 \AA$, which corresponds to sharing of two arsenate apical oxygen atoms with adjacent edge-sharing $\mathrm{Fe}(\mathrm{O}, \mathrm{OH})_{6}$ octahedra (Farquhar et al. 2002; Maillot et al. 2013; Manning et al. 2002). This is a likely coordination environment based on the high iron content $\left(1.3 \mathrm{~g} \mathrm{~kg}^{-1}\right)$ and the strong affinity of $\mathrm{As}^{\mathrm{V}}$ for ferric (hydr)oxides (Dixit and Hering 2003). The ${ }^{2} \mathrm{C}$ coordination has previously been shown to be the dominant mode of arsenate tetrahedra adsorption to octahedra of iron (hydr)oxides including goethite, lepidocrocite, hematite, hydrous ferric oxide (HFO), ferrihydrite, schwertmannite, and arsenic-loaded jarosite (Paktunc and Dutrizac 2003; Root et al. 2007; Savage et al. 2000; Sherman and Randal 2003). The MTW-BC As-Fe distance at $3.37 \AA$ was similar to the distance observed for amorphous ferric arsenate (3.36 $\AA$ ) and scorodite (3.37 $\AA$ ) (Foster et al. 1998), consistent with a ferric arsenate surface complex (Voegelin et al. 2007). However, the coordination number of 1.2 , which was lower than the expected 2, indicated some arsenic was not in ${ }^{2} \mathrm{C}$ coordination. A possible sink for arsenic is the mineral schwertmannite, which has been shown to form ${ }^{2} \mathrm{C}$ surface complexes as well as structural incorporation. Arsenate oxyanions can displace hydrogenbonded sulfate ions in the schwertmannite tunnel structure (accepting an akaganeite structure), which forms an outersphere complex that is not probed with EXAFS, and would result in a lower coordination number from EXAFS fits (Burton et al. 2009; Maillot et al. 2013), consistent with the results of the present work.

\section{Morphological alteration of BC}

Micrographs show BC and MTW-BC (48 h) at different magnifications and on different $\mathrm{BC}$ particles (Fig. 7a-f). The unreacted $\mathrm{BC}$ shows no detectable secondary mineral phases (Fig. 7a). The MTW-BC (48 h) showed a strong emergent signal from $\mathrm{S}$ and $\mathrm{Fe}$ in association with the precipitated particles on the surface, consistent with the Fe XANES (Fig. 7e, f). Spherical neo-aggregates were observed and could indicate schwertmannite or goethite (Fig. 7b, f). The acicular crystals, consistent with either goethite or gypsum, were observed in the MTW-BC (Fig. 7c-d). Micrographs of BC and MTW$\mathrm{BC}$ show surface texture (Fig. 7 e, f). Carbon and oxygen were the two main elemental components in the $\mathrm{BC}$, with $\mathrm{Si}, \mathrm{K}$, and $\mathrm{Ca}$ contributing to the $\mathrm{X}$-ray spectrum collected by EDS (Fig. 7g), the MTW-BC(48 h) shows peaks of $\mathrm{S}$ and $\mathrm{Fe}$ that are not present in the unreacted $\mathrm{BC}$.

\section{Discussion}

\section{Effect of mine tailing water chemistry on biochar activation}

The oxic MTW, with low $\mathrm{pH}$ and high dissolved solids inclusive of elevated $\mathrm{Fe}^{3+}{ }_{(a q)}$ and $\mathrm{As}^{5+}{ }_{(a q)}$, is representative of AMD that ponds and seeps from sulfidic mine tailings. Dissolved arsenic in the prepared MTW from IKMHSS mine tailings far exceeds the recommended upper limit of $10 \mu \mathrm{g} \mathrm{L}^{-1}$ for potable water (WHO 2017), and in the absence of acid neutralization and a stable sorbent, $\mathrm{Fe}^{3+}$ and $\mathrm{As}^{5+}$ in AMD is labile and can contribute to groundwater contamination and offsite ecosystem degradation. The abundant carbonate, oxalate, and carboxyl groups including calcite, whewellite, and $\mathrm{R}-\mathrm{COO}^{-}$functional sites in $\mathrm{BC}$ provide a strong proton buffering capacity (Yuan et al. 2011), making BC a beneficial amendment under acidic conditions including AMD. It was observed that calcite and whewellite disappeared or weakened in FTIR spectra and XRD diffractograms upon reaction with MTW (Figs. 2 and 3), evidence of BC contribution to mine tailing buffering during reaction. The $\mathrm{pH}$ buffering capacity of $\mathrm{BC}$ is evidenced by the fact that MTW $\mathrm{pH}$ was increased and maintained from about 3 to 4 (Fig. S1) despite ongoing $\mathrm{Fe}^{\mathrm{III}}$ hydrolysis reactions. The $\mathrm{pKa}$ values of carbonic acid, oxalic acid, and common carboxylic acids are $6.4,4.3\left(\mathrm{pKa}_{2}\right.$, whereas $\mathrm{pKa}_{1}=1.25$ ), and ca. 4.5 , respectively, and the abundant acid-base reactions of $\mathrm{BC}$ act to maintain a $\mathrm{pH}$ of just above 4 in the AMD modeled here. Whereas dissolved ferric iron is stable under strongly acidic conditions, it is insoluble under the mildly acid $\mathrm{pH}$ environment resulting from reaction with alkaline BC. The acid-neutralizing capacity of BC promotes $\mathrm{Fe}^{3+}$ hydrolysis and ferric (hydr)oxide precipitation, and the $\mathrm{BC}$ surface provides a high interfacial area for mediating nucleation and growth of the surface precipitates. Upon formation, ferric (hydr)oxides on the BC surface provide highaffinity surface sites (octahedral $\mathrm{Fe}^{\mathrm{III}}-\mathrm{OH}$ groups) for innersphere, bidentate, binuclear complexation of dissolved arsenate, thereby limiting contaminant flux.

\section{Iron oxide-activated biochar and arsenic removal mechanisms}

Dissolved iron in MTW, $[\mathrm{Fe}]=1340 \pm 50 \mathrm{mg} \mathrm{kg}^{-1}$, far exceeded the concentration of iron solubilized from the $\mathrm{BC}$ itself; water-soluble $\mathrm{BC}[\mathrm{Fe}]$ was $0.006 \mathrm{mg} \mathrm{kg}^{-1}$. The $\mathrm{BC}$ was reacted at 1:100 solid to solution with MTW, where dissolved iron from MTW was more than six orders of magnitude greater than that from the $\mathrm{BC}$ alone, making any $\mathrm{Fe}$ released from the biochar negligible. Effectively, all of the dissolved and reactive iron was from the MTW. The relative decrease in the $\mathrm{BC}$ contribution to the Fe XANES spectra is attributed to neoformed $\mathrm{Fe}^{\mathrm{III}}$ surface precipitates, and we assume there 
Fig. 7 SEM images of unreacted $\mathrm{BC}$ and MTW-BC-48 h. a BC; b MTW-BC with acicular crystals and spherical neo-aggregates; $\mathbf{c}$ and $\mathbf{d}$ MTW-BC with acicular neo-precipitates; e BC; f MTWBC $48 \mathrm{~h}$ with surface coatings; $\mathbf{g}$ EDS of box in $\mathbf{e} ; \mathbf{h}$ EDS of box in f. Scale given in micrograph pan$\mathrm{el}$; collected at $20 \mathrm{kV}$ and $7.5 \mathrm{~mm}$ working distance; EDS collected at $10 \mathrm{kV}$
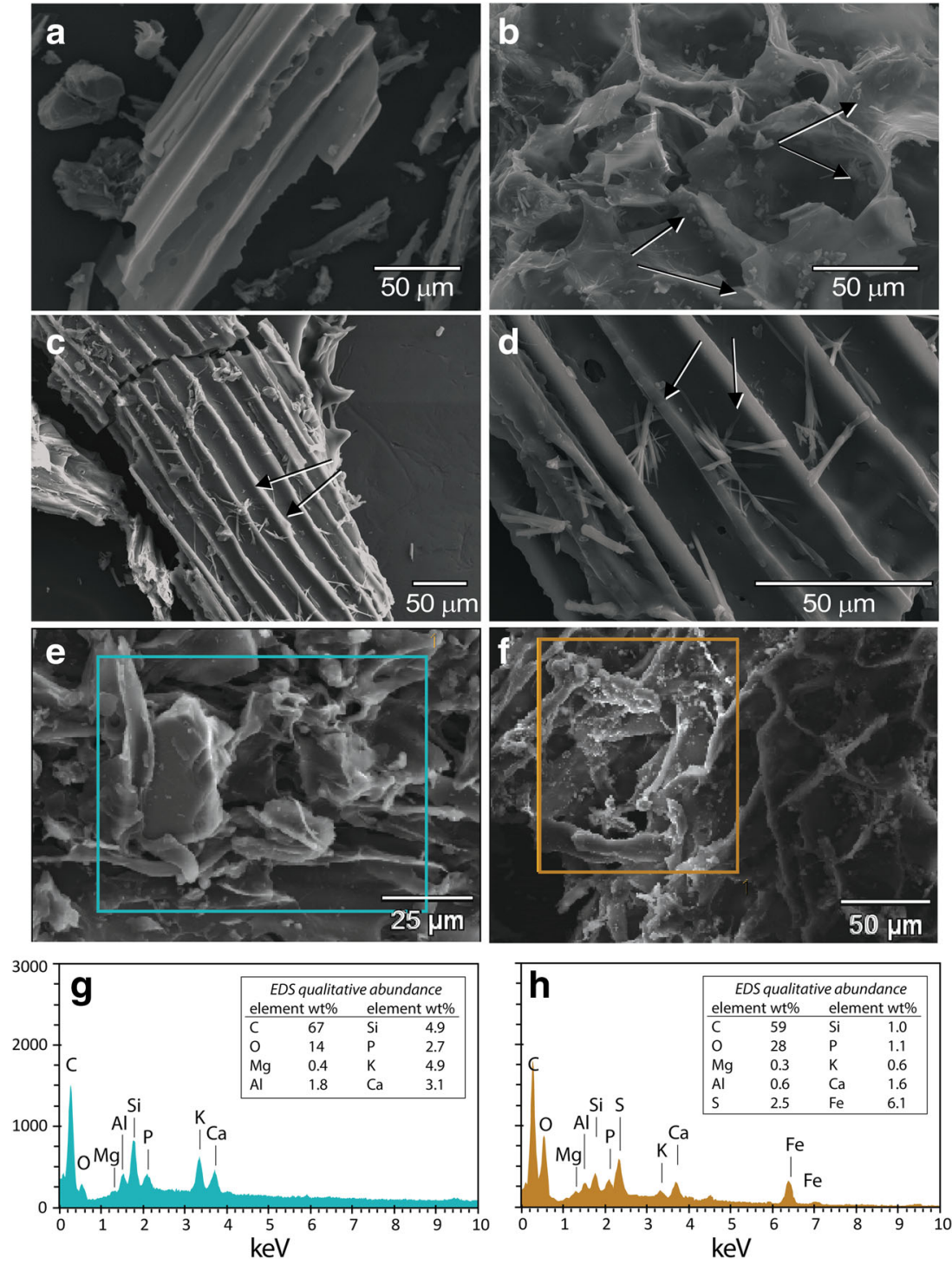

was no change in the original BC iron species. At the end of the experiment ( $48 \mathrm{~h}$ ), the initial iron and neo-precipitate iron, determined by XANES, were approximately equivalent in mass, indicating about $800 \mathrm{mg}$ of newly precipitated ferric hydroxy(sulf)oxide partitioned to each kilogram of BC, which became progressively available for surface complexation with adsorptive arsenic. Control treatments showed that MTW did not produce ferric precipitates within $48 \mathrm{~h}$ in the absence of $\mathrm{BC}$, and dissolved arsenate $\left(54.7 \mu \mathrm{g} / \mathrm{L} \mathrm{HAsNa} \mathrm{O}_{4} \cdot 7 \mathrm{H}_{2} \mathrm{O}\right)$ added to $\mathrm{BC}$ in the absence of MTW was not removed at either $\mathrm{pH} 3$ or 5.8 (Fig. S8), which brackets the $\mathrm{pH}$ values observed in the MTW-BC experiments. Hence, the arsenic remediation effect was the result MTW-BC interaction.

When MTW was added to BC, iron partitioning to the solid phase was observed within the first $15 \mathrm{~min}$ (Fig. 5). Dissolved iron and arsenic partitioned to the solid phase at an Fe:As mol ratio of about 525 (Fig. S9), and the sequestered arsenic surface coverage was far below the capacity of the phases observed (goethite $<$ schwertmannite $<$ ferrihydrite) (Asta et al. 2009; Burton et al. 2009; Wilkie and Hering 1996). This indicates that MTW-activated BC has additional unused capacity for arsenic removal, and that the surface loading capacity of iron-activated BC should be further investigated. Ferrihydrite and schwertmannite have been shown to have higher arsenate adsorption capacities than goethite does, but the short-range-ordered phases are considered less robust sequestration sites due to their meta-stability, and tendency to undergo Ostwald ripening to more thermodynamically stable mineral species like goethite (Das et al. 2013). Because arsenic was not removed by unactivated BC, components of mine tailing water, specifically the high dissolved iron, play a vital role in the ability of $\mathrm{BC}$ to remove arsenic from water, and activated $\mathrm{BC}$ can be an effective remediation media where dissolved iron concentrations greatly exceed those of dissolved arsenic. This condition is met by many AMD systems. 
Despite the fact that ferric adsorption sites were apparently in excess of adsorptive arsenic, kinetic data were best fit to a pseudo-second-order model, suggesting adsorption site limitations. This can be attributed to the fact that the kinetically limiting step for arsenic removal was the precursor reaction of ferric mineral plaque formation, which, as indicated by $\mathrm{C}$ NEXAFS and STXM results, was nucleated at carboxyl-Cenriched sites in BC (Fig. 3). Surface carboxyl groups in BC are known to have an affinity for polyvalent metal cations and can stabilize metals at surface functional groups (Uchimiya et al. 2012). Additionally, because biochar is redox-active due to its quinone and aromatic structures, it may have the potential to catalyze abiotic surface redox reactions and facilitate ferric hydroxy(sulf)oxide formation from ferrous iron by $\mathrm{Fe}^{\mathrm{II}}$ oxidation at electron-accepting surfaces (Cataldo et al. 2018; Klüpfel et al. 2014; Yu et al. 2015; Zhao et al. 2019b). The redox active surface did not, however, promote any reduction of arsenate to the more toxic and labile arsenite (Fig. 6). Whereas the MTW solution in the current study was dominated by $\mathrm{Fe}^{\mathrm{III}}$ aqueous species and the possible oxidation of ferrous iron by $\mathrm{BC}$ was not specifically probed, it has been reported previously that $\mathrm{Fe}^{2+}{ }_{(\text {aq }}$ can form complexes at anionic $-\mathrm{C}(=\mathrm{O})$ - surface sites of $\mathrm{BC}$, where electron transfer to the BC produces an insoluble ferric crust (Kappler et al. 2014). Whereas native $\mathrm{BC}$, comprising graphitic sheets and negatively charged functional groups, eschews oxyanion interaction (Lehmann and Joseph 2009; Uchimiya et al. 2012), the ferric-oxide-activated-BC surface complexes promote oxyanion arsenate surface complexation and coprecipitation at iron-activated nucleation sites (Fig. 5). The inner-sphere surface complexation of arsenate by iron oxide is proposed to be a two-step process of initial monodentate ligand exchange with hydroxide at an apical oxygen site of an $\mathrm{Fe}^{\mathrm{III}}$ octahedron, followed by a second similar ligand exchange reaction on a neighboring $\mathrm{Fe}^{\mathrm{III}}$ octahedron, resulting in a bidentate, binuclear surface complex (Grossl et al. 1997). The high stability of the bidentate surface complex stabilizes the arsenate against desorption, and it should persist under environmental conditions that favor ferric solids.

The dissolved iron species in the MTW was mostly ( 94\%) ferric, which upon sorption on BC precipitated as ferrihydrite, schwertmannite, and/or goethite. When goethite was suppressed in the thermodynamic model to simulate the kinetic retardation of its precipitation (i.e., $<1 \mathrm{~h}$ reaction), the metastability fields of ferrihydrite and schwertmannite are shown to have a $\mathrm{pH}$-dependent stability boundary at $\mathrm{pH} 5.8$, with ferrihydrite stable at higher $\mathrm{pH}$ and schwertmannite stable at lower $\mathrm{pH}$ (Fig. 8). The $\mathrm{pH}$ at the end of the experiment was above 4 , and at equilibrium under these acid conditions, ferrihydrite is expected to transform to goethite or schwertmannite (Jönsson et al. 2005; Yee et al. 2006). During the initial stages of the reaction, from $15 \mathrm{~min}$ to $1 \mathrm{~h}$, the fraction of ferrihydrite was generally unchanged, but at 6

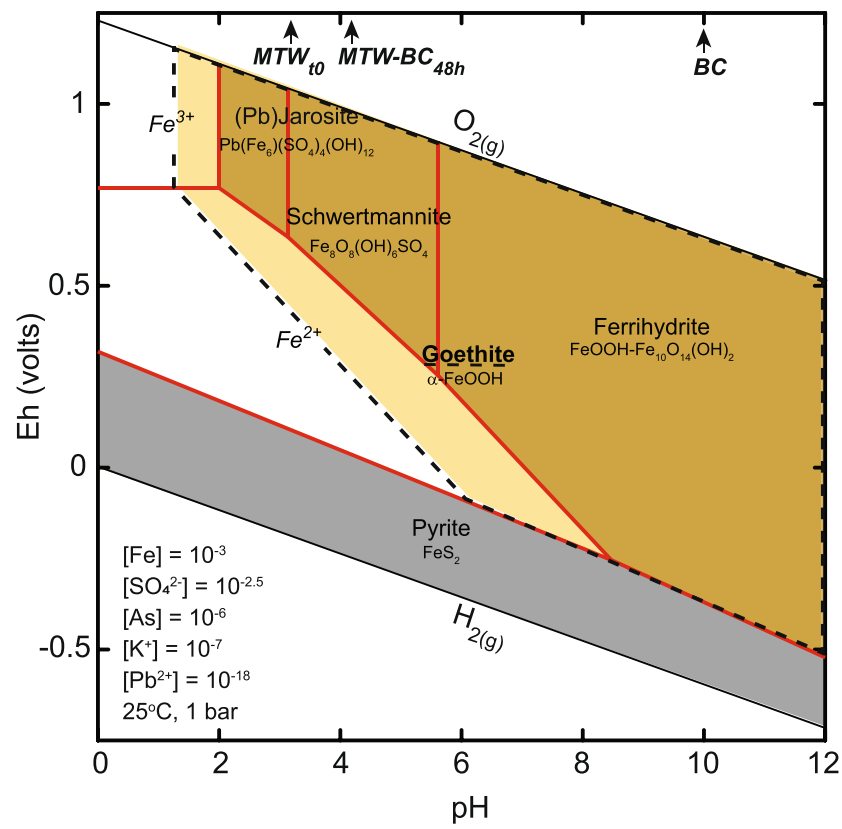

Fig. 8 Predominance diagram showing aqueous (unshaded) and solid (shaded) iron species calculated as a function of $E_{\mathrm{h}}$ and $\mathrm{pH}$ at $25^{\circ} \mathrm{C}$ and $1 \mathrm{~atm}$ with $[\mathrm{Fe}]_{\text {total }}=10^{-3},\left[\mathrm{SO}_{4}{ }^{2-}\right]=10^{-2.5},[\mathrm{As}]=10^{-6},\left[\mathrm{~K}^{+}\right]=$ $10^{-7}$, and $\left[\mathrm{Pb}^{2+}\right]=10^{-18}$ using the LLNL thermodynamic database. Modeled solid lines bound the metastable solid phases when goethite is suppressed. The hatched area bounds the stability field of goethite when it is included in the model. The $\mathrm{pH}$ of MTW, MTW-BC at $48 \mathrm{~h}$, and BC are indicated at the top $x$-axis with arrows

h, schwertmannite was observed as the fraction of ferrihydrite decreased. It is not clear if ferrihydrite was transforming to schwertmannite or if schwertmannite was co-precipitating with ferrihydrite. It can be inferred that while the relative contribution of the iron present in the unreacted $\mathrm{BC}$ to the iron XANES signal decreased, the abundance did not change; rather, the contribution from neo-ferric precipitates increased in relative contribution to the spectra. Therefore, about $60 \%$ of the iron XANES signal was from neo-ferric hydroxy(sulf)oxides after $6 \mathrm{~h}$. At $6 \mathrm{~h}$, ferrihydrite decreased in relative predominance and goethite and schwertmannite appeared. The transformation of ferrihydrite to goethite did not inhibit the rate of arsenic removal, which indicates that iron-activated BC has high absorption capacity. In the MTW reaction, high sulfate activity promotes schwertmannite stability (Fig. 8), and the likelihood of its conversion to goethite or hematite is diminished. Competing ions may impact arsenic removal, and sulfate sorption to dairy waste $\mathrm{BC}$ has been shown to exhibit increased affinity with increased acidity (Zhao et al. 2019a). It is therefore expected that sulfate will compete with oxyanion arsenate for surface complexation on forest waste biochar in low-pH waters.

We propose that soluble arsenic was sequestered in the solid phase following an initial first step of ferrihydrite nucleation on $\mathrm{BC}$ followed by arsenic absorption during the first reaction hour. Ferrihydrite then transformed to goethite at $\mathrm{pH}$ 
4 and room temperature, where the rate of ferrihydrite transformation is driven by dissolution and reprecipitation at $\mathrm{pH} 3-$ 5 (Cudennec and Lecerf 2006; Das et al. 2013). The metastability of schwertmannite at the end of the experiment is attributed to the rate of transformation to goethite being inhibited by high aqueous sulfate activity, low $\mathrm{pH}$, and ambient temperature (Jönsson et al. 2005). The thermodynamically predicted stable iron phases, with respect to $\mathrm{pH}$ and redox (Eh, volts) under the environmental conditions of the kinetic experiment, included goethite under oxidizing conditions across a wide $\mathrm{pH}$ range (2 to 12 ) and $\mathrm{Fe}^{2+}{ }_{(a q)}$ under suboxic conditions, and at very low $\mathrm{pH}(<2.0), \mathrm{Fe}^{3+}{ }_{(a q)}$ is stable (Fig. 8). In the absence of BC, iron suspensions or sediments in MTW were not produced within $48 \mathrm{~h}$ and are not thermodynamically favorable; it is therefore expected that surface catalysis on BC was necessary for ferric solid nucleation and arsenic removal.

\section{Conclusions}

Biochar from pine forest waste produced at $450{ }^{\circ} \mathrm{C}$ proved to be effective at removing dissolved arsenic from AMD. This is the first work examining the substantial potential to employ unamended $\mathrm{BC}$ as an effective amendment for remediating mine drainage and tailing waters when both dissolved arsenate and ferric iron exist simultaneously. It was observed that the alkalinity of $\mathrm{BC}$ induced an increase of MTW pH, which caused dissolved ferric iron to become insoluble. As iron oxides precipitated at BC surfaces, goethite, ferrihydrite, and schwertmannite formed sorbate surface sites for arsenic removal. Arsenic adsorption kinetics were well described by a pseudo-second-order kinetic rate expression, consistent with chemisorption as the mechanism of arsenic removal from the aqueous phase. This investigation demonstrates that biochar is an effective remediation material for arsenic in AMD that is enriched in dissolved iron, and its use as a reactive barrier should be explored. Longer-term investigations are needed to examine the stability of arsenic absorbed by ferric oxide activated $\mathrm{BC}$ due to the meta-stability of the ferric solid phases.

Supplementary Information The online version contains supplementary material available at https://doi.org/10.1007/s11356-021-13869-8.

Acknowledgements This research was supported by the National Institute of Environmental Health Sciences (NIEHS) Superfund Research Program Grant 2 P42 ES04940. Portions of this research were carried out at Stanford Synchrotron Radiation Laboratory, a National User Facility operated by Stanford University on behalf of the U.S. Department of Energy, Office of Basic Energy Sciences. Electron microscopy and micro-X-ray analysis were carried out at the Kuiper Imaging Core facility managed by the Office for Research, Discovery \& Innovation and Arizona Research Laboratories. Jian Wang is thanked for providing support on the STXM SM beamline at the Canadian Light Source (CLS). CLS is supported by the Canada Foundation for Innovation, Natural Sciences and Engineering Research Council of
Canada, the University of Saskatchewan, the Government of Saskatchewan, Western Economic Diversification Canada, the National Research Council Canada, and the Canadian Institutes of Health Research. This research was supported by the China Scholarship Council (CSC, Grant No. 201607005142) and Fundamental Research Funds for the Central Universities (Grant No. 2682016CX092). We thank Mary K. Amistadi at ALEC for help with elemental analysis.

Author contribution D.W., R.R., and J.C. conceived and designed the study. D.W. conducted the wet chemistry experiments, infrared spectroscopy analyses, and associated data analysis. R.R. conducted the X-ray diffraction and spectroscopy measurements, infrared spectroscopic measurements, and associated data analyses. D.W. drafted the manuscript. R.R. and J.C. contributed to editing and writing the manuscript. All authors read and approved the final manuscript.

Funding This research was supported by the National Institute of Environmental Health Sciences (NIEHS) Superfund Research Program Grant 2 P42 ES04940 and was supported by the China Scholarship Council (CSC, Grant No. 201607005142) and Fundamental Research Funds for the Central Universities (Grant No. 2682016CX092).

Data availability The datasets used and/or analyzed during the current study are available from the corresponding author on reasonable request.

\section{Declarations}

\section{Ethics approval and consent to participate Not applicable.}

Consent for publication Not applicable.

Competing interests The authors declare that they have no competing interests

Open Access This article is licensed under a Creative Commons Attribution 4.0 International License, which permits use, sharing, adaptation, distribution and reproduction in any medium or format, as long as you give appropriate credit to the original author(s) and the source, provide a link to the Creative Commons licence, and indicate if changes were made. The images or other third party material in this article are included in the article's Creative Commons licence, unless indicated otherwise in a credit line to the material. If material is not included in the article's Creative Commons licence and your intended use is not permitted by statutory regulation or exceeds the permitted use, you will need to obtain permission directly from the copyright holder. To view a copy of this licence, visit http://creativecommons.org/licenses/by/4.0/.

\section{References}

Ahmad M, Lee SS, Lee SE, Al-Wabel MI, Tsang DCW, Ok YS (2016) Biochar-induced changes in soil properties affected immobilization mobilization of metals/metalloids in contaminated soils. J Soils Sediments 17:717-730. https://doi.org/10.1007/s11368-015-1339-4

Amen R et al (2020) A critical review on arsenic removal from water using biochar-based sorbents: the significance of modification and redox reactions. Chem Eng J 396:125195. https://doi.org/10.1016/j. cej.2020.125195

Artiola JF, Rasmussen C, Freitas R (2012) Effects of a biochar-amended alkaline soil on the growth of romaine lettuce and bermudagrass. Soil Sci 177:561-570. https://doi.org/10.1097/SS. 0b013e31826ba908 
Asta MP, Cama J, Martínez M, Giménez J (2009) Arsenic removal by goethite and jarosite in acidic conditions and its environmental implications. J Hazard Mater 171:965-972. https://doi.org/10.1016/j. jhazmat.2009.06.097

ATSDR (2011) Substance Priority List. Agency for Toxic Substances and Disease Registry. http://www.atsdrcdc.gov/SPL/index.html

Bakshi S, Banik C, Rathke S, Laird D (2018) Arsenic sorption on zerovalent ironbiochar complexes. Water Res 137:153-163. https://doi. org/10.1016/j.watres.2018.03.021

Beaulieu BT, Savage KS (2005) Arsenate adsorption structures on aluminum oxide and phyllosilicate mineral surfaces in smelterimpacted soils. Environ Sci Technol 39:3571-3579. https://doi. org/10.1021/es048836f

Beesley L, Moreno-Jimenez E, Gomez-Eyles JL (2010) Effects of biochar and greenwaste compost amendments on mobility, bioavailability and toxicity of inorganic and organic contaminants in a multi-element polluted soil. Environ Pollut 158:2282-2287. https://doi.org/10.1016/j.envpol.2010.02.003

Beesley L, Marmiroli M, Pagano L, Pigoni V, Fellet G, Fresno T, Vamerali T, Bandiera M, Marmiroli N (2013) Biochar addition to an arsenic contaminated soil increases arsenic concentrations in the pore water but reduces uptake to tomato plants (Solanum lycopersicum L.). Sci Total Environ 454-455:598-603. https://doi. org/10.1016/j.scitotenv.2013.02.047

Bethke CM (2008) Geochemical and biogeochemical reaction modeling, 2nd edn. Cambridge University Press, Cambridge

Brennan JK, Bandosz TJ, Thomson KT, Gubbins KE (2001) Water in porous carbons. Colloids Surf A Physicochem Eng Asp 187-188: 539-568. https://doi.org/10.1016/S0927-7757(01)00644-6

Burton ED, Bush RT, Johnston SG, Watling KM, Hocking RK, Sullivan LA, Parker GK (2009) Sorption of $\operatorname{arsenic}(V)$ and $\operatorname{arsenic}(\mathrm{III})$ to schwertmannite. Environ Sci Technol 43:9202-9207. https://doi. org/10.1021/es902461x

Carlin DJ, Naujokas MF, Bradham KD, Cowden J, Heacock M, Henry HF, Lee JS, Thomas DJ, Thompson C, Tokar EJ, Waalkes MP, Birnbaum LS, Suk WA (2016) Arsenic and environmental health: state of the science and future research opportunities. Environ Health Perspect 124:890-899. https://doi.org/10.1289/ehp.1510209

Cataldo S, Gianguzza A, Milea D, Muratore N, Pettignano A, Sammartano S (2018) A critical approach to the toxic metal ion removal by hazelnut and almond shells. Environ Sci Pollut Res 25:4238-4253. https://doi.org/10.1007/s11356-017-0779-3

Cudennec Y, Lecerf A (2006) The transformation of ferrihydrite into goethite or hematite, revisited. J Solid State Chem 179:716-722. https://doi.org/10.1016/j.jssc.2005.11.030

Das S, Jean J-S, Kar S (2013) Bioaccessibility and health risk assessment of arsenic in arsenic-enriched soils, Central India. Ecotoxicol Environ Saf 92:252-257. https://doi.org/10.1016/j.ecoenv.2013.02. 016

Delany JM, Lundeen SR (1990) The LLNL thermochemical database. Lawrence Livermore National Laboratory Report UCRL-21658

Dixit S, Hering JG (2003) Comparison of arsenic(V) and arsenic(III) sorption onto iron oxide minerals: implications for arsenic mobility. Environ Sci Technol 37:4182-4189. https://doi.org/10.1021/ es030309t

Farquhar ML, Charnock JM, Livens FR, Vaughan DJ (2002) Mechanisms of arsenic uptake from aqueous solution by interaction with goethite, lepidocrocite, mackinawite, and pyrite: an x-ray absorption spectroscopy study. Environ Sci Technol 36:1757-1762. https://doi.org/10.1021/es010216g

Forray FL, Smith AML, Navrotsky A, Wright K, Hudson-Edwards KA, Dubbin WE (2014) Synthesis, characterization and thermochemistry of synthetic $\mathrm{Pb}-\mathrm{As}, \mathrm{Pb}-\mathrm{Cu}$ and $\mathrm{Pb}-\mathrm{Zn}$ jarosites. Geochim Cosmochim Acta 127:107-119
Foster AL, Brown GE, Tingle TN, Parks GA (1998) Quantitative arsenic speciation in mine tailings using $\mathrm{X}$-ray absorption spectroscopy. Am Mineral 83:553-568

Gao X, Root RA, Farrell J, Ela W, Chorover J (2013) Effect of silicic acid on arsenate and arsenite retention mechanisms on 6-L ferrihydrite: a spectroscopic and batch adsorption approach. Appl Geochem 38: $110-120$

Grossl PR, Eick M, Sparks DL, Goldberg S, Ainsworth CC (1997) Arsenate and chromate retention mechanisms on goethite. 2 . Kinetic evaluation using a pressure-jump relaxation technique. Environ Sci Technol 31:321-326. https://doi.org/10.1021/ es9506541

Hammond CM, Root RA, Maier RM, Chorover J (2018) Mechanisms of arsenic sequestration by Prosopis juliflora during the phytostabilization of metalliferous mine tailings. Environ Sci Technol 52:1156-1164. https://doi.org/10.1021/acs.est.7b04363

Hammond CM, Root RA, Maier RM, Chorover J (2020) Arsenic and iron speciation and mobilization during phytostabilization of pyritic mine tailings. Geochim Cosmochim Acta 286:306-323. https:// doi.org/10.1016/j.gca.2020.07.001

Hayes SM, Root RA, Perdrial N, Maier RM, Chorover J (2014) Surficial weathering of iron sulfide mine tailings under semi-arid climate. Geochim Cosmochim Acta 141:240-257. https://doi.org/10.1016/ j.gca.2014.05.030

Helgeson HC, Kirkham DH, Flowers GC (1981) Theoretical prediction of the thermodynamic behaviour of aqueous electrolytes at high pressures and temperatures. IV. Calculation of activities coefficients, osmotic coefficients, and apparent molal and standard and relative partial molal properties to $5 \mathrm{~kb}$ and $600{ }^{\circ} \mathrm{C}$. Am J Sci 281:12411516

Hu B, Song Y, Wu S, Zhu Y, Sheng G (2019) Slow released nutrientimmobilized biochar: a novel permeable reactive barrier filler for Cr(VI) removal. J Mol Liq 286:110876. https://doi.org/10.1016/j. molliq.2019.04.153

Ibrahim M, Khan S, Hao X, Li G (2016) Biochar effects on metal bioaccumulation and arsenic speciation in alfalfa (Medicago sativa L.) grown in contaminated soil. Int J Environ Sci Technol 13:24672474. https://doi.org/10.1007/s13762-016-1081-5

ICDD (2005) JCPDS Powder Diffraction File 2 Database. International Centre for Diffraction Data, Newton Square, PA, USA

Ilavsky J (2012) Nika: software for two-dimensional data reduction. J Appl Crystallogr 45:324-328. https://doi.org/10.1107/ s0021889812004037

Jin Q et al (2020) Grape pomace and its secondary waste management: biochar production for a broad range of lead $(\mathrm{Pb})$ removal from water. Environ Res 186:109442. https://doi.org/10.1016/j.envres. 2020.109442

Jönsson J, Persson P, Sjoberg S, Lovgren L (2005) Schwertmannite precipitated from acid mine drainage: phase transformation, sulphate release and surface properties. Appl Geochem 20:179-191

Kappler A, Wuestner ML, Ruecker A, Harter J, Halama M, Behrens S (2014) Biochar as an electron shuttle between bacteria and Fe(III) minerals. Environ Sci Technol Lett 1:339-344. https://doi.org/10. 1021/ez5002209

Kelly CN, Peltz CD, Stanton M, Rutherford DW, Rostad CE (2014) Biochar application to hardrock mine tailings: soil quality, microbial activity, and toxic element sorption. Appl Geochem 43:35-48. https://doi.org/10.1016/j.apgeochem.2014.02.003

Klüpfel L, Keiluweit M, Kleber M, Sander M (2014) Redox properties of plant biomass-derived black carbon (biochar). Environ Sci Technol 48:5601-5611. https://doi.org/10.1021/es500906d

Lehmann J, Joseph S (eds) (2009) Biochar for environmental management: science and technology. Earthscan, London \& Sterling

Lehmann J, Liang B, Solomon D, Lerotic M, Luizão F, Kinyangi J, Schäfer T, Wirick S, Jacobsen C (2005) Near-edge X-ray absorption fine structure (NEXAFS) spectroscopy for mapping nano-scale 
distribution of organic carbon forms in soil: application to black carbon particles. Glob Biogeochem Cycles 19. https://doi.org/10. 1029/2004gb002435

Lerotic M, Mak R, Wirick S, Meirer F, Jacobsen C (2014) MANTiS: a program for the analysis of X-ray spectromicroscopy data. J Synchrotron Radiat 21:1206-1212. https://doi.org/10.1107/ S1600577514013964

Li F, Li Z, Mao P, Li Y, Li Y, McBride MB, Wu J, Zhuang P (2018) Heavy metal availability, bioaccessibility, and leachability in contaminated soil: effects of pig manure and earthworms. Environ Sci Pollut Res Int 26:20030-20039. https://doi.org/10.1007/s11356018-2080-5

Li X, Zhang X, Wang X, Cui Z (2019) Phytoremediation of multi-metal contaminated mine tailings with Solanum nigrum L. and biochar/ attapulgite amendments. Ecotoxicol Environ Saf 180:517-525. https://doi.org/10.1016/j.ecoenv.2019.05.033

Liang C, Gascó G, Fu S, Méndez A, Paz-Ferreiro J (2016) Biochar from pruning residues as a soil amendment: effects of pyrolysis temperature and particle size. Soil Tillage Res 164:3-10. https://doi.org/10. 1016/j.still.2015.10.002

Liu X et al (2019) Impact of biochar amendment on the abundance and structure of diazotrophic community in an alkaline soil. Sci Total Environ 688:944-951. https://doi.org/10.1016/j.scitotenv.2019.06. 293

Lu K, Yang X, Gielen G, Bolan N, Ok YS, Niazi NK, Xu S, Yuan G, Chen X, Zhang X, Liu D, Song Z, Liu X, Wang H (2016) Effect of bamboo and rice straw biochars on the mobility and redistribution of heavy metals $(\mathrm{Cd}, \mathrm{Cu}, \mathrm{Pb}$ and $\mathrm{Zn})$ in contaminated soil. J Environ Manag 186:285-292. https://doi.org/10.1016/j.jenvman.2016.05. 068

Maillot F, Morin G, Juillot F, Bruneel O, Casiot C, Ona-Nguema G, Wang Y, Lebrun S, Aubry E, Vlaic G, Brown GE Jr (2013) Structure and reactivity of As(III)- and As(V)-rich schwertmannites and amorphous ferric arsenate sulfate from the Carnoule's acid mine drainage, France: comparison with biotic and abiotic model compounds and implications for As remediation. Geochim Cosmochim Acta 104:310-329

Majzlan J, Navrotsky A, McCleskey RB, Alpers CN (2006) Thermodynamic properties and crystal structure refinement of ferricopiapite, coquimbite, rhomboclase, and $\mathrm{Fe}_{2}\left(\mathrm{SO}_{4}\right)_{3}\left(\mathrm{H}_{2} \mathrm{O}\right)_{5}$. Eur J Mineral 18:175-186. https://doi.org/10.1127/0935-1221/ 2006/0018-0175

Manning BA, Fendorf SE, Bostick BC, Susarez D (2002) Arsenic(III) oxidation and arsenic(V) adsorption reactions on synthetic birnessite. Environ Sci Technol 36(5):976-981

Mendez MO, Maier RM (2008) Phytostabilization of mine tailings in arid and semiarid environments - an emerging remediation technology. Environ Health Perspect 116:278-283

Meng J, Tao M, Wang L, Liu X, Xu J (2018) Changes in heavy metal bioavailability and speciation from a $\mathrm{Pb}-\mathrm{Zn}$ mining soil amended with biochars from co-pyrolysis of rice straw and swine manure. Sci Total Environ 633:300-307. https://doi.org/10.1016/j.scitotenv. 2018.03.199

Ona-Nguema G, Morin G, Juillot F, Calas G, Brown GE (2005) EXAFS analysis of arsenite adsorption onto two-line ferrihydrite, hematite, goethite, and lepidocrocite. Environ Sci Technol 39:9147-9155. https://doi.org/10.1021/es050889p

Paktunc D, Dutrizac JE (2003) Characterization of arsenate-for-sulfate substitution in synthetic jarosite using X-ray diffraction and X-ray absorption spectroscopy. Can Mineral 41:905-919. https://doi.org/ 10.2113/gscanmin.41.4.905

Puga AP, Melo LCA, de Abreu CA, Coscione AR, Paz-Ferreiro J (2016) Leaching and fractionation of heavy metals in mining soils amended with biochar. Soil Tillage Res 164:25-33. https://doi.org/10.1016/j. still.2016.01.008
Ravel B, Newville M (2005) ATHENA, ARTEMIS, HEPHAESTUS: data analysis for X-ray absorption spectroscopy using IFEFFIT. J Synchrotron Radiat 12:537-541

Rehr JJ (1993) Recent developments in multiple-scattering calculations of XAFS and XANES Japan. J Appl Phys 32:8-12

Root RA, Dixit S, Campbell KM, Jew AD, Hering JG, O'Day PA (2007) Arsenic sequestration by sorption processes in high-iron sediments. Geochim Cosmochim Acta 71:5782-5803

Root RA, Hayes SM, Hammond CM, Maier RM, Chorover J (2015) Toxic metal(loid) speciation during weathering of iron sulfide mine tailings under semi-arid climate. Appl Geochem 62:131-149. https://doi.org/10.1016/j.apgeochem.2015.01.005

Savage KS, Tingle TN, O'Day PA, Waychunas GA, Bird DK (2000) Arsenic speciation in pyrite and secondary weathering phases, Mother Lode Gold District, Tuolumne County, California. Appl Geochem 15:1219-1244

Sherman D, Randal SR (2003) Surface complexation of $\operatorname{arsenic}(V)$ to iron(III) (hydr)oxides: structural mechanism from ab initio molecular geometries and EXAFS spectroscopy. Geochim Cosmochim Acta 67:4223-4230

Solis-Dominguez FA, White SA, Hutter TB, Amistadi MK, Root RA, Chorover J, Maier RM (2012) Response of key soil parameters during compost-assisted phytostabilization in extremely acidic tailings: effect of plant species. Environ Sci Technol 46:1019-1027. https://doi.org/10.1021/es202846n

Solomon D et al (2012) Micro- and nano-environments of carbon sequestration: multi-element STXM-NEXAFS spectromicroscopy assessment of microbial carbon and mineral associations. Chem Geol 329: 53-73. https://doi.org/10.1016/j.chemgeo.2012.02.002

Stookey L (1970) Ferrozine - a new spectrophotometric reagent for iron Anal Chem 42(7):779-781. https://doi.org/10.1021/ac60289a016

Uchimiya M, Bannon DI, Wartelle LH (2012) Retention of heavy metals by carboxyl functional groups of biochars in small arms range soil. J Agric Food Chem 60:1798-1809. https://doi.org/10.1021/ jf2047898

Valentin-Vargas A, Chorover J, Maier RM (2013) A new standard-based polynomial interpolation (SBPIn) method to address gel-to-gel variability for the comparison of multiple denaturing gradient gel electrophoresis profile matrices. J Microbiol Methods 92:173-177. https://doi.org/10.1016/j.mimet.2012.12.001

Voegelin A, Weber F-A, Kretzschmar R (2007) Distribution and speciation of arsenic around roots in a contaminated riparian floodplain soil: micro-XRF element mapping and EXAFS spectroscopy. Geochim Cosmochim Acta 71:5804-5820

Wang S, Gao B, Zimmerman AR, Li Y, Ma L, Harris WG, Migliaccio KW (2015) Removal of arsenic by magnetic biochar prepared from pinewood and natural hematite. Bioresour Technol 175:391-395. https://doi.org/10.1016/j.biortech.2014.10.104

Webb SM (2006) SixPACK: a graphical user interface for XAS analysis using IFEFFIT. Phys Scr T115:1011-1014

WHO (2017) Guidelines for drinking-water quality, 4th edn. World Health Organization, Geneva ISBN 978-92-4-154995-0

Wilkie JA, Hering JG (1996) Adsorption of arsenic onto hydrous ferric oxide: effects of adsorbate/adsorbent ratios and co-occurring solutes. Colloids Surf A Physicochem Eng Asp 107:97-110. https://doi.org/ 10.1016/0927-7757(95)03368-8

Wu C, Cui M, Xue S, Li W, Huang L, Jiang X, Qian Z (2018) Remediation of arsenic-contaminated paddy soil by iron-modified biochar. Environ Sci Pollut Res Int 25:20792-20801. https://doi. org/10.1007/s11356-018-2268-8

Xiao X, Chen B, Chen Z, Zhu L, Schnoor JL (2018) Insight into multiple and multilevel structures of biochars and their potential environmental applications: a critical review. Environ Sci Technol 52:50275047. https://doi.org/10.1021/acs.est.7b06487 
Yee N, Shaw S, Benning L, Nguyen TH (2006) The rate of ferrihydrite transformation to goethite via the Fe(II) pathway. Am Mineral 91: 92-96. https://doi.org/10.2138/am.2006.1860

Yoon K, Cho D-W, Tsang DCW, Bolan N, Rinklebe J, Song H (2017) Fabrication of engineered biochar from paper mill sludge and its application into removal of arsenic and cadmium in acidic water. Bioresour Technol 246:69-75. https://doi.org/10.1016/j.biortech. 2017.07.020

Yu L, Yuang Y, Tang J, Wang Y, Zhou S (2015) Biochar as an electron shuttle for reductive dechlorination of pentachlorophenol by Geobacter sulfurreducens. Sci Rep 5:16221-16221. https://doi.org/ $10.1038 /$ srep 16221

Yuan J-H, Xu R-K, Zhang H (2011) The forms of alkalis in the biochar produced from crop residues at different temperatures. Bioresour Technol 102:3488-3497. https://doi.org/10.1016/j.biortech.2010. 11.018
Zhang M, Gao B, Varnoosfaderani S, Hebard A, Yao Y, Inyang M (2013) Preparation and characterization of a novel magnetic biochar for arsenic removal. Bioresour Technol 130(1):457-462. https://doi. org/10.1016/j.biortech.2012.11.132

Zhao B, Xu H, Ma F, Zhang T, Nan X (2019a) Effects of dairy manure biochar on adsorption of sulfate onto light sierozem and its mechanisms. RSC Adv 9:5218-5223. https://doi.org/10.1039/ C8RA08916G

Zhao J, Shen X-J, Domene X, Alcañiz J-M, Liao X, Palet C (2019b) Comparison of biochars derived from different types of feedstock and their potential for heavy metal removal in multiple-metal solutions. Sci Rep 9:9869. https://doi.org/10.1038/s41598-019-46234-4

Publisher's note Springer Nature remains neutral with regard to jurisdictional claims in published maps and institutional affiliations. 